\title{
HIGHLY POROUS HYBRID COMPOSITE HYDROGELS BASED ON CELLULOSE AND 1,10-PHENANTHROCYANINE OF Zn(II): SYNTHESIS AND CHARACTERIZATION WITH WAXS, FTIR, ${ }^{13} \mathrm{C}$ CP/MAS NMR AND SEM
}

\author{
ALEKSANDRA MIKHAILIDI, ${ }^{*}$ NATALIA SAPRYKINA, ${ }^{* *}$ MAXIM MOKEEV, ${ }^{* *}$ \\ ANDREY ZINCHENKO*** and NINA KOTELNIKOVA ${ }^{* *}$ \\ *St. Petersburg State University of Industrial Technologies and Design, St. Petersburg 191186, Russia \\ ** Institute of Macromolecular Compounds, Russian Academy of Sciences, \\ St. Petersburg 199004, Russia \\ **** Pt. Petersburg State Technological Institute, St. Petersburg 190013, Russia \\ \Corresponding author: A. Mikhailidi, amikhailidi@yahoo.com
}

Dedicated to 100 years since the birth of Acad. Prof. Cr. I. Simionescu, founder of the Department of Pulp and Paper in Romania and Cellulose Chemistry and Technology journal

\begin{abstract}
Hybrid composite hydrogels were synthesized by immobilization of 1,10-phenanthrocyanine zinc(II) complex in cellulose hydrogels. The hydrogels exhibited long-term stability, high water retaining capacity and porosity, which were determined using chemical methods. They were characterized with wide-angle X-ray scattering (WAXS), Fourier transform infrared spectroscopy (FTIR), high-resolution solid-state ${ }^{13} \mathrm{C}$ CP/MAS NMR spectroscopy and scanning electron microscopy (SEM). According to FTIR analysis, the immobilization of the complex in the hydrogels led to its interaction with the cellulose inside the matrices of the hydrogels. Additional crystallization of the cellulose in the hydrogels occurred during the formation of the composite hydrogels, as revealed with WAXS. The surface and morphology of the cross-sections of the hydrogels, as well as the pore distribution and pore size, were defined with SEM. The SEM study also ascertained the impact of the molecular mass of the embedded complex on the efficiency of the immobilization.
\end{abstract}

Keywords: cellulose, hydrogels, 1,10-phenanthrocyanine Zn(II) complex, WAXS, FTIR, ${ }^{13} \mathrm{C}$ CP/MAS NMR, SEM

\section{INTRODUCTION}

Bio-based materials for medical and pharmaceutical application, particularly scaffolds for drug delivery, are a key topic of research interest nowadays. The use of renewable resources, such as the most abundant in nature and sustainable cellulose, is a crucial point in science and industry. Cellulose has attracted considerable attention as the strongest potential candidate feedstock for bio-based polymeric material production. The growing interest to develop new bio-based cellulosic materials is also due to the easy accessibility of cellulose, its low cost, biodegradability and environmental friendliness. Although many studies have been published over the past decades and significant progress in the production of biopolymers based on different cellulosic forms has been achieved, the search for new methods of obtaining cellulose-based materials still remains a challenge of ongoing research..$^{1-7}$ This has been confirmed by the EU Discussion on "Top 20 innovative biobased products" in December 2018, where among others, cellulose has been considered as one of the most important feedstocks to produce novel prospective cellulose-based materials. ${ }^{8}$

There are many ways to move from biomass to advanced bio-based cellulose materials. The most up-to-date and popular are chemical routes, which provide new perspectives for upgrading biomass to bio-based products. The chemical modification 
of cellulose is due to the high hydrophilicity of its surface and bulk, which is provided by a number of intra- and inter-chain $\mathrm{H}$-bonds connecting the hydroxyl groups. This defines its interactions with chemicals and its reactivity in various media. One of the directions of the structural and chemical modification of cellulose is the immobilization of the chemicals, including biomolecules onto cellulose, which leads to obtaining cellulose derivatives, conjugates, composites, etc. The attachment to cellulose hydroxyl groups involves the use of various substances depending on the aim of the immobilization. For instance, cyanogen bromide and transition metal salts have been used for enzyme immobilization. Other methods include attachment via carboxylic acid groups on cellulose derivatives, attachment to aliphatic amine derivatives, and attachment via alkyl halide derivatives. ${ }^{9-11}$ However, in our opinion, there is no all-purpose method for the immobilization of biomolecules onto cellulose.

The cellulose matrix can be also chemically altered by embedding metal components into the structure. These issues are not new, nor are they historical artefacts. The use of cellulose as a scaffold for metal particles has been described in numerous publications. So, composites of microcrystalline cellulose of different origin and hydrate cellulose with embedded nanoparticles of nickel, cobalt, copper and silver have been obtained and described in previous studies. ${ }^{12-16}$ Depending on the metal nanoparticles, the composites acquired catalytic, antibacterial, optical and other useful properties.

In the last decades, novel cellulose-based materials, such as hydrogels, have attracted much attention and have been extensively investigated because these biodegradable systems have numerous advantages. The hydrogels consist in one or more three-dimensional highly hydrated polymeric networks formed from macromolecular chains interconnected by chemical (covalent) bonds or physical interactions. The hydrogels have attracted special attention for water purification through adsorption, due to their high absorbency, porous structure, rich functional groups, and relatively low crystallinity. ${ }^{17}$ The super-swollen hydrogels based on natural polymeric materials are of interest as carriers of medicinal agents in antibacterial and antitumor therapy. The possibility of controlled dosed-out release of biologically active compounds (BAC) from the matrices of the hydrogels has directed great attention towards the study of hydrogels modified by BAC.

The majority of cellulose hydrogels have been derived from bacterial cellulose, due to the peculiarities of the synthesis and shape. ${ }^{18,19}$ In recent years, plant-derived cellulose has come to be also widely used to prepare hydrogels. The unique properties of hydrogels, namely, their high water-holding and absorption capacity, as well as sufficiently high stiffness, have been actively studied by various physical methods. The hydrogels are usually prepared from solutions of different native cellulose samples in various solvents, followed by subsequent regeneration from the solutions. ${ }^{20}$ Some major aspects concerning hydrogels have been considered in numerous publications, including a number of reviews (see, for instance ${ }^{17,21,22}$ ). The first aspect concerned the mechanism of their preparation via regeneration from solutions of pristine natural celluloses.

The incorporation of different components into the gel system endows the resulting hybrid hydrogels with the ability to remove various aquatic pollutants, such as metal ions (transition or radioactive), dyes (cationic or anionic), and other ions (nitrogenous or phosphorous). ${ }^{17} \mathrm{Zinc}$ compounds have recently attracted attention for embedding into composite materials, due to their special electrical, photocatalytic, optical and antibacterial properties. $^{23-25}$ In most cases, the synthesis of $\mathrm{ZnO}$ has been performed in heteroand homogeneous media in different matrices, including cellulose, using the most well-known thermochemical, ultrasonic or sol-gel methods. Thus, $\mathrm{ZnO}$ has been synthesized on cotton and fique fibers and on bacterial cellulose as semispherical nanoparticles of various shapes. ${ }^{23-25}$ In many publications, it was found that the obtained composites have exhibited useful properties, including antibacterial activities. Literature analysis has also shown that powder cellulose or cellulose derivatives have mainly been used as matrices, however, the range of the zinc compounds used for the intercalation into the cellulose matrix has been limited to a small number and the composition of the compounds was scarcely varied.

Complexation of $\mathrm{Zn}$ (II) with different ligands has been also studied and coordination compounds, the binuclear zinc(II) 1,10phenanthrocyanine $\quad[($ phen $) n Z n(\mu-$ phencyanine $) \mathrm{Zn}$ (phen) $\left.\mathrm{n}(\mathrm{OAc})_{4} \cdot \mathrm{HOAc}\right](\mathrm{n}=0-2)$ complexes, have been recently prepared and 
described by Demidov et $a l^{26,27}$ The novel organic-inorganic hybrid complexes were synthesized by the hydrothermal reaction and first described by Liu et al. ${ }^{28}$ The synthesis of electronrich transition metal 1,10-phenanthrocyanines is based on the reaction of metal-promoted nondehydrogenative $\mathrm{C}\left(\mathrm{sp}^{2}\right) \mathrm{H}-\mathrm{C}\left(\mathrm{sp}^{2}\right) \mathrm{H}$-coupling of coordinated 1,10-phenanthroline and can be performed in homoleptic and heteroleptic cationic complexes of d-elements in solutions, including aqueous solutions of amines, in melts of respective complexes-precursors and in the binary melts complex metal halide-[2,9- $\mathrm{Me}_{2}-$ phen] $0.5 \mathrm{H}_{2} \mathrm{O}$. The nature of the metal ions essentially impacts the conditions of formation of 1,10-phenanthrocyanine complexes of d-elements, their structure, stability and reactivity. ${ }^{26,27}$ Electron-rich coordination compounds of delements, $\mathrm{Pd}(\mathrm{II}), \mathrm{Pt}(\mathrm{II}), \mathrm{Co}(\mathrm{II}), \mathrm{Zn}(\mathrm{II})$ and $\mathrm{Ag}(\mathrm{I})$, based on 1,10-phenanthrocyanates, seem to exhibit antibacterial, antifungal, antiviral and anticancer properties.

In our previous paper, ${ }^{29}$ we described the synthesis of new hybrid composites of superswollen cellulose hydrogels with binuclear electron-rich $\quad \mathrm{C}\left(\mathrm{sp}^{2}\right) \mathrm{H}$-coupled $\quad$ zinc(II) $\quad 1,10$ phenanthrocyanine $\quad\left[(\mathrm{phen}){ }_{\mathrm{n}} \mathrm{Zn}(\mu\right.$ phencyanine $\left.) \mathrm{Zn}(\text { phen })_{\mathrm{n}}(\mathrm{OAc})_{4} \cdot \mathrm{HOAc}\right]$ complexes via diffusion-adsorption immobilization onto the hydrogels. The use of cellulose hydrogels as scaffolds for the synthesis of composite materials is principally a new direction in cellulose research, and applying zinc complexes for the immobilization in cellulose hydrogels has never been studied. Considering the first preliminary results, it was proposed that the immobilization of the complexes in the hydrogels led to their interaction with the cellulose in the matrices of the hydrogels.

The goal of the present paper was to present the new results obtained in updating the method for the synthesis of the novel cellulose composite hydrogels by the immobilization of zinc complexes and to study their functional and chemical compositions by high-resolution solidstate ${ }^{13} \mathrm{C} \mathrm{CP} / \mathrm{MAS}$ NMR spectroscopy and Fourier transform infrared spectroscopy (FTIR). The supramolecular structure of the composite hydrogels was determined with wide-angle X-ray scattering (WAXS), and scanning electron microscopy (SEM) was used to characterize the morphology of the pristine and synthesized hydrogels. In general, this work had the aim to study the feasibility of using cellulose hydrogels as matrix for incorporating bioactive compounds of the complex type.

\section{EXPERIMENTAL Materials}

Zinc acetate dihydrate $\left(\mathrm{CH}_{3} \mathrm{COO}\right)_{2} \mathrm{Zn} \cdot 2 \mathrm{H}_{2} \mathrm{O}$ [bis(acetato-O,O')diaquazinc (II)] and 1,10phenanthroline monohydrate $\left(\mathrm{C}_{12} \mathrm{H}_{8} \mathrm{~N}_{2}\right) \cdot \mathrm{H}_{2} \mathrm{O}$ $\left(\mathrm{C}_{12} \mathrm{H}_{10} \mathrm{~N}_{2} \mathrm{O}\right)$ (below, 1,10-phen) were purchased from Merck (Merck KGaA, Germany). The chemicals used for the preparation of the hydrogels, including anhydrous $\mathrm{LiCl}$, purum p.a., were purchased from Fluka, and N,N-dimethylacetamide was purchased from Sigma-Aldrich. Glacial acetic acid (HOAc) was obtained from a chemical enterprise in Russia. All the chemicals were of analytical grade. They were used as received without further purification. Distilled water was used in all the experiments. The syntheses were performed at room or elevated temperature under ambient reaction conditions.

\section{Methods}

Synthesis of complexes of 1,10-phenanthrocyanines of Zn(II) [below 1,10-phencyanine Zn(II)]

The complexes of 1,10-phencyanine $\mathrm{Zn}$ (II) exist in several forms and they were used in three forms here. They were prepared by a method of metal-mediated non-dehydrogenative $\mathrm{C}\left(\mathrm{sp}^{2}\right) \mathrm{H}$-coupling of 1,10 phenanthrolines in solutions or in melts of the corresponding precursors, described elsewhere. ${ }^{26,27}$ The synthesis of 1,10-phencyanine $\mathrm{Zn}$ (II) included several steps and is briefly described below.

\section{Synthesis of purple 1,10-phencyanine Zn(II)}

The initial compounds were: zinc acetate dihydrate $\mathrm{Zn}\left(\mathrm{CH}_{3} \mathrm{COO}\right)_{2}$ and 1,10-phenanthroline monohydrate $\left(\mathrm{C}_{12} \mathrm{H}_{8} \mathrm{~N}_{2}\right) \cdot \mathrm{H}_{2} \mathrm{O}$. In the zinc acetate dihydrate, the $\mathrm{Zn}$ atom adopts a distorted octahedral structure coordinated with two $\mathrm{O}$ atoms of water and four $\mathrm{O}$ atoms of the acetate groups. In other words, zinc is octahedral, wherein both acetate groups are bidentate.

Two-stage thermosynthesis of 1,10-phencyanine $\mathrm{Zn}$ (II) was executed by heating in the melt. The synthesis was performed through thermoactivation of the zinc acetate dihydrate mixed with the coordinated 1,10-phenanthroline. In the first stage, the complex of 1,10-phen with $\mathrm{Zn}(\mathrm{II})$ acetate as intermediates was formed, according to Scheme 1:

$\mathrm{Zn}^{2+}(\mathrm{OAc})_{2} \cdot 2 \mathrm{H}_{2} \mathrm{O}+\mathrm{n}(1,10$-phen $) \cdot \mathrm{H}_{2} \mathrm{O} \rightarrow \mathrm{Zn}^{2+}(1,10$ phen $)_{\mathrm{n}}(\mathrm{OAc})_{2}+(\mathrm{n}+2) \mathrm{H}_{2} \mathrm{O}$,

where $\mathrm{n}=1-3$.

In the second stage, the complex of 1,10-phen with $\mathrm{Zn}$ (II) acetate was converted into purple binuclear 1,10-phencyanine $\mathrm{Zn}(\mathrm{II})$, according to Scheme 2 (1,10phencyanine $\mathrm{Zn}$ (II) was actually an adduct with the acetic acid):

$2 \mathrm{Zn}^{2+}(\text { phen })_{\mathrm{n}}(\mathrm{OAc})_{2} \quad \rightarrow \quad\left[(\text { phen })_{\mathrm{n}-1} \mathrm{Zn}^{2+}(\mu-\right.$ phencyanine $\left.) \mathrm{Zn}^{2+}(\text { phen })_{\mathrm{n}-1}(\mathrm{OAc})_{4}\right]$, 
where $\mathrm{n}=1-3, \mu$-phencyanine is dihydro-bi-1,10phenanthroline.

This complex formed aqua complex ions in aqueous media:

$\left[\left(\mathrm{H}_{2} \mathrm{O}\right)_{2}(\right.$ phen $) \mathrm{Zn}^{2+}(\mu-$

phencyanine $) \mathrm{Zn}^{2+}($ phen $\left.)\left(\mathrm{H}_{2} \mathrm{O}\right)_{2}\right]^{4+}$

Synthesis of yellow-brown 1,10-phencyanine Zn(II)

The synthesis of yellow-brown hydroacetate complexes of 1,10-phencyanine $\mathrm{Zn}$ (II) was carried out by dissolving the purple complexes in glacial acetic acid at room temperature. The excess of the glacial acetic acid (HOAc) was removed by evaporation at 28 ${ }^{\circ} \mathrm{C}$. A schematic representation of the reactions in this process is shown in Scheme 3:

$\left[(\text { phen })_{\mathrm{n}} \mathrm{Zn}^{2+}(\mu\right.$-phencyanine $\left.) \mathrm{Zn}^{2+}(\text { phen })_{\mathrm{n}}(\mathrm{OAc})_{4}\right] \quad+$ $\mathrm{HOAc} \rightarrow$

$\left[(\right.$ phen $){ }_{n} \mathrm{Zn}^{2+}(\mu-$

phencyanine $\left.) \mathrm{Zn}^{2+}(\text { phen })_{\mathrm{n}}(\mathrm{OAc})_{4} \cdot \mathrm{HOAc}\right]$,

where $\mu$-phencyanine is a derivative of dihydro-bi1,10-phenanthroline.

The yellow-brown 1,10-phencyanine $\mathrm{Zn}$ (II) complex was used for immobilization in the cellulose hydrogels. The chemical content of the elements in the immobilized complexes was determined by elemental analysis and their MM was calculated, according to the chemical composition.

\section{Preparation and some properties of the cellulose hydrogels ${ }^{20}$}

Super-swollen hydrogels of cellulose were used as polymer matrixes for the immobilization of the complexes. The hydrogels were prepared in vitro from lignocellulose pulps of various origins, using shortlength flax fibers (PF) and bleached sulfite hardwood pulp (PH). These pulps were hydrolyzed with an aqueous solution of nitric acid to prepare powder celluloses. Direct dissolution of the powders of PF and $\mathrm{PH}$ in the solvent $\mathrm{N}, \mathrm{N}$-dimethylacetamide/LiCl (DMAc/LiCl) was followed by regeneration from solutions. To monitor the gelation of the regenerated samples, the solutions were poured into dishes and left under ambient conditions for 5-7 days. The gels were formed by absorbing the solvent and finally the swollen samples did not change anymore. They were rinsed with water, herewith the solvent was replaced with the water. Thus, the formation of the hydrogels was performed without any anticoagulants, due to spontaneous self-assembly and aggregation of cellulose chains. The obtained hydrogels (below, PF and $\mathrm{PH}$ pristine hydrogels prepared from $\mathrm{PF}$ and $\mathrm{PH}$, respectively) were stable for as long as needed when stored in water. A digital image of the $\mathrm{PH}$ hydrogel is shown in Figure 1, a. Swollen hydrogels prepared in situ are massive transparent elastic samples. They can be prepared in different forms depending on the shape of the vessel, wherein they were synthesized. The hydrogels are super-absorbents and they can retain up to $2800 \mathrm{wt} \%$ of water. ${ }^{20}$ The high porosity and the developed specific surface relate to the main properties of the hydrogels as well. A schematic drawing of cellulose chains in the hydrogel with included molecules of water $\left(\mathrm{Cell}-\mathrm{OH} \cdots \mathrm{H}_{2} \mathrm{O}\right)$ is shown in Figure 1, b. Depending on the objectives, the hydrogels could be air-dried, dried in a vacuum oven at $40{ }^{\circ} \mathrm{C}$ or freeze-dried.

\section{Immobilization of zinc complexes into the cellulose hydrogels}

The super-swollen hydrogels regenerated from the $\mathrm{PH}$ and $\mathrm{PF}$ solutions in $\mathrm{DMAc} / \mathrm{LiCl}$ were used as scaffolds for the immobilization of hydroacetate complexes of 1,10-phencyanine zinc(II), using the diffusion-adsorption method. The optimal mode of the synthesis was found to be for the complex $\left[(\right.$ phen $) \mathrm{Zn}^{2+}(\mu$-phencyanine $) \mathrm{Zn}^{2+}($ phen $\left.)(\mathrm{OAc})_{4}\right]$ in the form of aqueous ion $\left[\left(\mathrm{H}_{2} \mathrm{O}\right)_{2}(\right.$ phen $) \mathrm{Zn}^{2+}(\mu-$ phencyanine $) \mathrm{Zn}^{2+}$ (phen) $\left(\mathrm{H}_{2} \mathrm{O}\right)_{2}{ }^{4+}$ depicted in Figure 2 . According to the elemental analysis, the complex contained the following amounts of the elements: $\mathrm{C}=$ $60.69 \mathrm{wt} \% ; \mathrm{H}=4.21 \mathrm{wt} \% ; \mathrm{N}=9.76 \mathrm{wt} \%, \mathrm{Zn}=11.39$ wt $\%$. The molecular mass (MM) of the complex was $1147.830 \mathrm{~g} / \mathrm{mol}$.
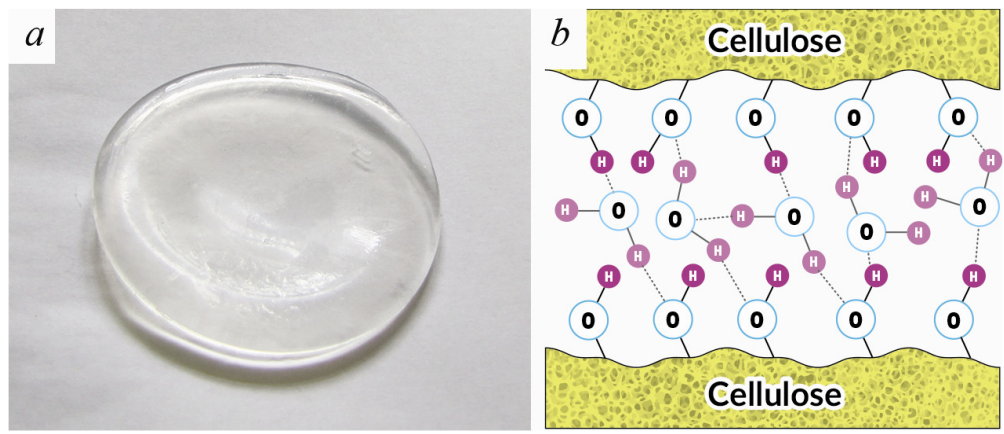

Figure 1: Digital image of the super-swollen PH pristine hydrogel (a) and schematic illustration of cellulose chains with included molecules of water $\left(\mathrm{Cell}-\mathrm{OH} \cdots \mathrm{H}_{2} \mathrm{O}\right)$ in the hydrogel $(b)^{32}$ 


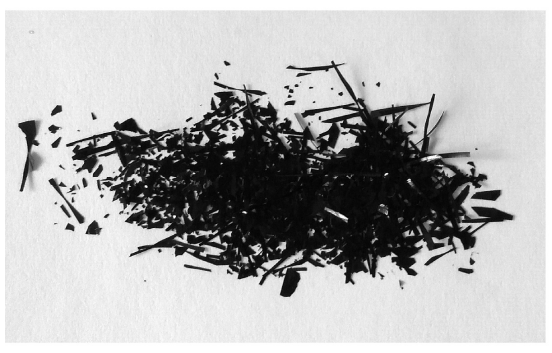

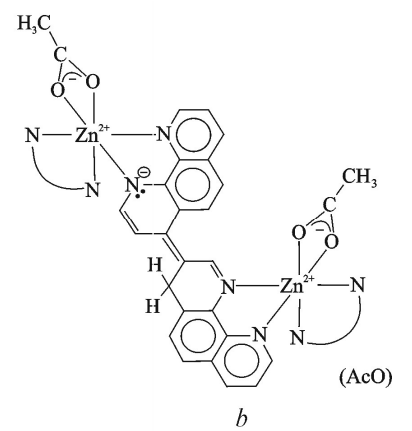

Figure 2: Digital image of the crystals of the purple precursor 1,10-phencyanine $\mathrm{Zn}(\mathrm{II})$ (a), and schematic structure of this complex $(b)^{29}$

The reaction was performed under isothermal conditions at $\mathrm{T}=28{ }^{\circ} \mathrm{C}$, as briefly described earlier. ${ }^{29}$ The impact of the reaction time and concentration of the complex in the solution on the completeness of the reaction was monitored varying the duration of the immobilization and the concentration of the complex. We describe here shortly an example synthesis of the composite hydrogel applied for both pristine hydrogels. The synthesis time was varied from $5 \mathrm{~min}$ to $180 \mathrm{~h}$, the concentration of the complex was varied from 0.10 to $1.50 \mathrm{wt} \%$. The optimal conditions were determined. The aqueous solution of the complex with the concentration of $0.48 \mathrm{wt} \%$ was put into the reaction vessel and a small slice of the hydrogel was added. The cellulose content in the hydrogel was $0.24 \mathrm{wt} \%$, which corresponded to the molar aspect ratio of $0.3: 1$. The liquid module was 10 . The reaction vessel was isolated from the atmosphere to avoid the evaporation of water. The equilibrium concentration of the complex in the hydrogel matrix was reached after $90 \mathrm{~h}$. When the synthesis was completed, the obtained hydrogel Cell/1,10-phencyanine $\mathrm{Zn}$ (II) was removed from the solution, placed into distilled water and then rinsed repeatedly and thoroughly with water. Thus, the synthesis procedure of the composite hydrogels was one-pot, simple and did not require any special techniques or equipment. Both PF and PH hydrogels obtained in the syntheses will be named below as PF and $\mathrm{PH}$ composite hydrogels, respectively.

\section{Characterization}

Equilibrium water content $(E W C)$ in the pristine and composite hydrogels

EWC is an important characteristic of swollen hydrogels. The water absorbed by hydrogels is quantitatively represented by EWC by using the equation below: ${ }^{30}$

$E W C=\left(m_{s}-m_{1}\right) \cdot m_{s}^{-1}$

where $m_{s}$ is the mass of the swollen hydrogel at time t at the equilibrium, and $m_{1}$ is the mass of the freezedried hydrogel. The EWC values were expressed in \% as an average of not less than three measurements.

The residual water content $(\mathrm{RW})$ in the freeze-dried hydrogels was calculated as follows:

$$
R W=\left(m_{1}-m_{0}\right) \cdot m_{1}^{-1}
$$

where $m_{l}$ is the mass of the freeze-dried hydrogel, and $m_{0}$ is the mass of the cellulose in the hydrogel. The $\mathrm{RW}$ values were expressed also in $\%$ as an average of two measurements.

\section{Hydrogel porosity}

The overall porosity of the hydrogels, i.e. the proportion of sample volume occupied by pores, was calculated, according to the following equation:

$P_{t}=1-\left(m_{0} \cdot P^{-1} \cdot L^{-1} \cdot \rho^{-1}\right)$

where $m_{0}$ is the weight of the freeze-dried hydrogel, $\mathrm{g}$, $P$ is the square of the surface of the hydrogel, $\mathrm{cm}^{2}, L$ is the thickness of the hydrogel, $\mathrm{cm}$, and $\rho$ is the density of cellulose $\left.\left(\rho=1.561 \mathrm{~g} \cdot \mathrm{cm}^{-3}\right)\right)^{31}$ The $P_{t}$ values were calculated as an average of two measurements.

Wide-angle X-ray scattering (WAXS), high-resolution solid-state ${ }^{13} \mathrm{C} C P / M A S$ NMR spectroscopy, Fourier transform IR spectroscopy (FTIR) and scanning electron microscopy (SEM)

The structure and properties of the pristine and synthesized composite hydrogels were studied by FTIR and high-resolution solid-state ${ }^{13} \mathrm{C}$ CP/MAS NMR spectroscopy, WAXS and SEM.

To characterize the crystalline structure of the hydrogels, an X-ray diffraction study was performed at the University of Helsinki. The WAXS setup consists of a sealed X-ray copper tube, which generates monochromatic $\mathrm{CuK} \alpha$ radiation with the wavelength of $1.541 \AA(\lambda)$, and a two-dimensional MAR345 image plate (Marresearch GmbH, Norderstedt, Germany) for detection, i.e. the measurements were conducted using the perpendicular transmission geometry. The distance between the sample and the image plate was $120 \mathrm{~mm}$. By using slits, the beam size was adapted to be $0.5 \mathrm{X}$ $0.55 \mathrm{~mm}^{2}$. The length of the scattering vector (q-range) was calibrated using a calibration sample lanthanum hexaboride and was found to be 0.3-3.4 $\AA^{-1}$, corresponding to the scattering angle range of $4.2-50^{\circ}$. The hydrogels were measured in the swollen state and were also dried using the freeze-drying technique. The swollen and freeze-dried hydrogels were measured as 
they were, because any changes in the morphology of the hydrogels could lead to alteration of their morphological or crystalline structure and crystal width. All measurements were duplicated. To determine the degree of crystallinity (DC) of the samples, the amorphous fitting analysis was used. ${ }^{32}$ Some explanations regarding the calculation will be given in the Results and Discussion in the WAXS part. The peak width was calculated, according to the Scherrer equation. ${ }^{33}$

Solid-state ${ }^{13} \mathrm{C} \quad \mathrm{CP} / \mathrm{MAS}$ NMR spectra were recorded under magic angle spinning at ambient temperature on an Avance II-500WB spectrometer (Bruker), operating at $125.8 \mathrm{MHz}$ for ${ }^{13} \mathrm{C}$. Samples were packed into $4 \mathrm{~mm}$ zirconium rotors and spun at a $5-8 \mathrm{kHz}$ frequency. Single-contact ${ }^{1} \mathrm{H} \rightarrow{ }^{13} \mathrm{C}$ crosspolarization (CP) technique with $2 \mathrm{~ms}$ contact time was applied for ${ }^{13} \mathrm{C} \mathrm{CP}$-spectra recording with high power proton decoupling $100 \mathrm{kHz}$. All chemical shifts are given in ppm from tetramethylsilane.

FTIR spectroscopy was used to characterize the functional composition of the hydrogels. FTIR spectra were recorded with a Bruker IFS 88 FTIR spectrometer (Bruker, Germany). The spectra were taken in the reflection mode. The swollen and freeze-dried hydrogels were measured as they were. The spectra resulting from the measurements included 64 scans at a spectral resolution of $8 \mathrm{~cm}^{-1}$ between 600 and $4000 \mathrm{~cm}^{-}$

1 . The ATR-FTIR spectra were recorded using a micro MiracleTM ATR attachment for the FTIR spectrometer.

The morphology of the hydrogels was examined both on the surface and on the specimen thickness slices with SEM. Electron micrographs were taken with a Supra 55VP (Zeiss, Germany) scanning electron microscope at a voltage of $15-30 \mathrm{kV}$. The freeze-dried hydrogels were fixed on a carbon substrate in a special box and sputtered in argon using a gold target on the Quorum device. The secondary electron mode (SE2) was used to study morphology.

Energy dispersive micro-X-ray spectral analysis (SEM-EDS) was applied to determine the elemental compositions of the samples and individual phases using an INCA Energy microanalysis system with an X-Max 80 detector (Oxford, Great Britain), equipped with a microscope SUPRA 55VP. To identify the phases in the samples, spectra were taken both from the overall surfaces and from individual points on the surfaces, as well as from cross-sections of the samples.

Macroscopic images of the samples were obtained in normal light with digital cameras Canon Power Shot A3400 IS and Canon Power Shot SX20 IS (both Japan).

\section{RESULTS AND DISCUSSION}

Digital (a) and optical (b) images of the Cell/1,10-phencyanine $\mathrm{Zn}(\mathrm{II})$ synthesized after immobilization of the 1,10-phencyanine zinc(II) complex in the $\mathrm{PH}$ hydrogel ${ }^{29}$ are shown in Figure 3.

The composite hydrogels were uniformly coloured and maintained their shape and colour without collapsing throughout the long-term storage in water.

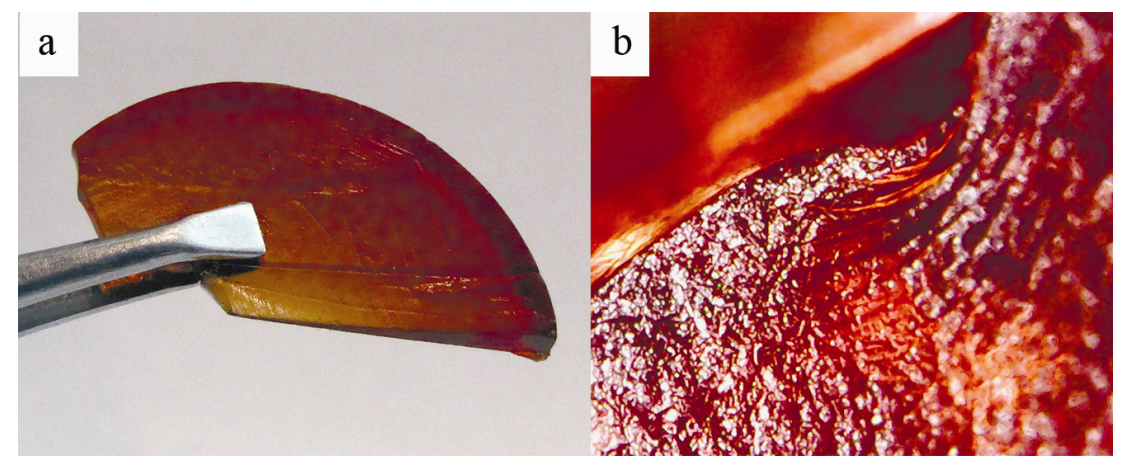

Figure 3: Digital (a) and optical (b) images of the PH composite hydrogel

Table 1

Maximum values of EWC, residual water content and porosity in the pristine and composite hydrogels

\begin{tabular}{lccc}
\hline Hydrogels & $E W C, \mathrm{wt} \%$ & $R W, \mathrm{wt} \%$ & $P_{t}, \%$ \\
\hline PH pristine & 2800 & 2.1 & 98.9 \\
PH composite & 1480 & 1.2 & 95.8 \\
PF pristine & 2500 & 1.8 & 97.4 \\
PF composite & 1240 & 1.1 & 94.6 \\
\hline
\end{tabular}


The hydrophilic nature of the cellulose hydrogels provided successful percolation paths for the adsorption of the complexes and, consequently, resulted in the homogeneous distribution of the complexes inside the hydrogels.

Equilibrium water content (EWC) in the pristine and composite hydrogels and their porosity

Table 1 shows the $E W C$ values and the contents of residual water $(R W)$ after freezedrying for the pristine and composite hydrogels. The EWC values for the pristine $\mathrm{PF}$ and $\mathrm{PH}$ hydrogels were $2500 \mathrm{wt} \%$ and $2800 \mathrm{wt} \%$, and the same freeze-dried hydrogels retained $1.8 \mathrm{wt} \%$ and $2.1 \mathrm{wt} \%$ of water, respectively. The results confirmed that the hydrogels were super-swollen systems and retained large amounts of water, while drying strongly affected the water retention of the hydrogels and EWC was drastically reduced.

The overall porosity values for the hydrogels are also shown in Table 1. The PH hydrogel has the highest $\mathrm{P}_{\mathrm{t}}$. The composite hydrogels also exhibited high swelling capacity. However, they revealed $E W C$ values of $1240 \mathrm{wt} \%$ and $1480 \mathrm{wt} \%$ (for PF and PH hydrogels, respectively), i.e. lower than those for the pristine hydrogels. The $\mathrm{P}_{t}$ values were also slightly lower and were $94.6 \%$ and $95.8 \%$ (for PF and PH composite hydrogels, respectively). In an earlier study ${ }^{20}$ we showed that cellulose hydrogels have a 3D structure and, due to their high porosity and water retention ability filling the empty spaces between the cellulose chains, they contain more than $97 \mathrm{wt} \%$ water of the total mass. A significant difference in the water retention values between the pristine and composite hydrogels seems to be due to differences in the chemical and supermolecular structure of the pristine and composite samples. However, these results confirm that the composite hydrogels can also absorb and retain large quantities of water and may be as well referred to the 3D structure systems. The water retaining capacity changed drastically upon drying of the freeze-dried composite hydrogels, similarly to the pristine hydrogels. The contents of residual water $(R W)$ in the hydrogels are also compared in Table 1 .

\section{Crystalline structure of the hydrogels: WAXS study}

Every set of the samples contained three specimens: the super-swollen pristine hydrogel, the composite hydrogel and the freeze-dried composite hydrogel. X-ray diffraction patterns (XDPs) of the swollen pristine hydrogels and water are shown in Figure $4 .^{32}$ The patterns of both $\mathrm{PF}$ and $\mathrm{PH}$ hydrogels didn't reveal any reflections of the cellulose lattice. The large content of water in the hydrogels hindered the major cellulose characteristic diffraction reflections. Instead, the XDPs resembled the diffraction patterns as smear halos of water within the $2 \theta 20-45^{\circ}$ range, although no difference was revealed between the obtained XDPs, which suggested that there was a full coincidence between the XDP profiles for the hydrogels and water.

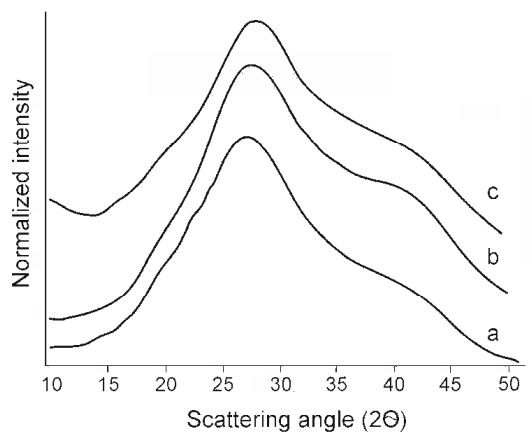

Figure 4: X-ray diffraction patterns for the super-swollen PF (a) and PH (b) pristine hydrogels and water (c) ${ }^{32}$

The diffraction patterns of the freeze-dried pristine and composite hydrogels are shown in Figure 5. There is a great difference between the scattering patterns of the freeze-dried PF (Fig. 5, a) and PH (Fig. 5, c) hydrogels. Recently, we showed that there were peaks located at $2 \theta=$ $12.3^{\circ}$ (1-10), $20.1^{\circ}(110), 22.5^{\circ}(020)$ and $\sim 34.8^{\circ}$ (004) on the XDP of the freeze-dried PF hydrogel, 
unlike in the case of the super-swollen hydrogel XDP (Fig. 4, a). ${ }^{32}$ The peaks were seen more clear-cut in the XDP of the freeze-dried PF hydrogel (Fig. 5, a) than in those of the freezedried PH hydrogel (Fig. 5, c).

This difference was confirmed, due to the deconvolution of the XDPs. As expected, the peaks were attributed to the cellulose II allomorph, since the dissolution of the original pulps encouraged structural reorganization of the cellulose I to cellulose II. The same peaks have been also found for many cellulose samples subjected to treatments with alkali solutions or to dissolution in various solvents, subsequent regeneration and then transformed to gels and to multiple shaped materials. ${ }^{34-38}$
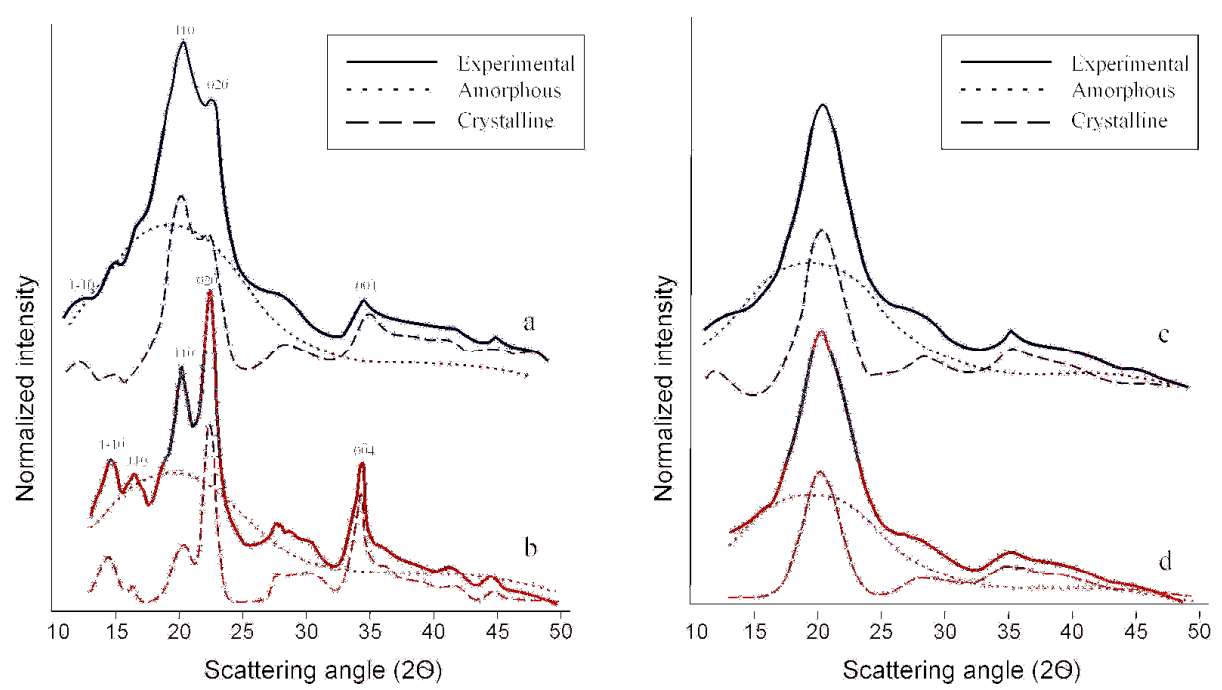

Figure 5: X-ray diffraction patterns for the freeze-dried hydrogels: PF pristine (a), PF composite (b), PH pristine (c) and PH composite (d) (full lines); dashed lines correspond to corrected deconvolution with separated amorphous and crystalline components on XRD curves that preceded the calculation of the crystallinity values ${ }^{32}$

The XDP of the freeze-dried PF composite hydrogel strongly differed from the XDP of the freeze-dried PF pristine hydrogel. There were two separated peaks at $2 \theta=14.9^{\circ}(1-10)$ and $16.8^{\circ}$ (110), characteristic of cellulose I. The other peak positions slightly changed, but they were located in general around $2 \theta=20.1^{\circ}(110), 22.5^{\circ}(020)$ and $\sim 34.6^{\circ}$ (004) on the XDP. The peaks had completely different shapes, intensity and intensity aspect ratio. In the pristine hydrogel, the intensity of the crystalline peak at $2 \theta=20.1^{\circ}$ (110) was higher than that at $2 \theta=22.5^{\circ}(020)$. In the composite hydrogel, the intensity of the peak at $22.5^{\circ}$ became much higher than the one at $20.1^{\circ}$. In other words, the peak height at $2 \theta=$ $20.1^{\circ}$ was essentially reduced, whereas the peak at $2 \theta=22.5^{\circ}$ was revived significantly. As it was mentioned, the peaks at $2 \theta=14.9^{\circ}, 16.8^{\circ}$ appeared simultaneously. This unusual result, despite the presence of a peak at $2 \theta=20.1^{\circ}$, typical of cellulose II, indicated that recrystallization with partial formation of cellulose I occurred. A similar phenomenon was also observed by studying cellulose crystalline transformation during the pretreatments of microcrystalline cellulose (MCC), which had the structure of cellulose I $\alpha$ before the treatment with ionic liquid $([\mathrm{C} 4 \mathrm{~min}] \mathrm{Cl}) .^{39}$ The authors established that pretreated and then regenerated MCC revealed conversion of the initial structure to cellulose $\mathrm{I} \beta$, i.e. revealed obvious recrystallization, which was accomplished via transformation of intermediate paracrystalline phase. T.G. Fawcett et al. studied a huge number of various cellulosic polymorphs and compared experimental and simulated XRDs of the samples. Along with other important results, the authors suggested that native cellulose samples are threecomponent systems consisting of cellulose $\mathrm{I} \alpha$, cellulose I $\beta$ and amorphous cellulose. ${ }^{40}$ These components can co-exist in different proportions, which vary depending on the sample processing. We propose that the increase in the intensity of the peaks at $2 \theta=14.9^{\circ}, 16.8^{\circ}, 22.5^{\circ}$ and a simultaneous significant decrease in the intensity of the peak at $2 \theta=20.1^{\circ}$ indicates that two structural components, cellulose I and II, coexist in the sample. 
The crystallinity values for the freeze-dried hydrogel were calculated, including the main reflections of cellulose II $1-10,110$ and 020 , as described in our paper. ${ }^{32}$ However, the large changes in the X-ray patterns of the freeze-dried $\mathrm{PF}$ composite, compared to those of the pristine hydrogels, created difficulties in determining reliably the crystallinity values. The corrected deconvolution with separated amorphous and crystalline components on the XRD curve of this hydrogel confirmed the presence of an essential amount of the component corresponding to cellulose I. On the basis of the data obtained, we cannot conclude herein what affected the crystallization and/or formation of a new crystalline phase in the composite hydrogel, the change in the cellulose structure stimulated by the immobilization of 1,10-phencyanine $\mathrm{Zn}$ (II) or the eventual crystallization of the complex itself in the matrix of the hydrogel. However, it can be concluded clearly that additional crystallization occurred during the formation of the composite.

In contrast to the XDPs of PF hydrogels, the XDPs of PH pristine and composite hydrogels exhibited similar shapes. The peaks had identical reflection positions, shapes and intensity. Due to the heavy overlapping of the cellulose II peaks, the width of the crystallites of the PH hydrogels could not be determined reliably. The WAXS results, i.e. crystallinity indices and the dimensions of the crystallites, for the samples are listed in Table 2. The crystallinity values determined on the basis of cellulose II were slightly higher for the composite hydrogels than those for the pristine hydrogels.

Table 2

Crystallinity values and crystallite sizes of cellulose in the freeze-dried pristine and composite hydrogels computed based on cellulose II reflections $1-10$ and $110^{*}$

\begin{tabular}{lcc}
\hline Hydrogels & $\begin{array}{c}\text { Crystallinity values, } \\
\text { cellulose II, } \%\end{array}$ & $\begin{array}{c}\text { Crystal size (width), } \\
\AA\end{array}( \pm 2 \AA)$ \\
\hline PH pristine & 29 & - \\
PH composite & 30 & - \\
PF pristine & 30 & $28(1-10) 34(110)$ \\
PF composite & 36 & $30(1-10) 32(110)$ \\
amorphous fitting method $( \pm 3 \%$ unit $){ }^{32}$ crystallite sizes were calculated using Scherrer's equation ${ }^{33}$
\end{tabular}

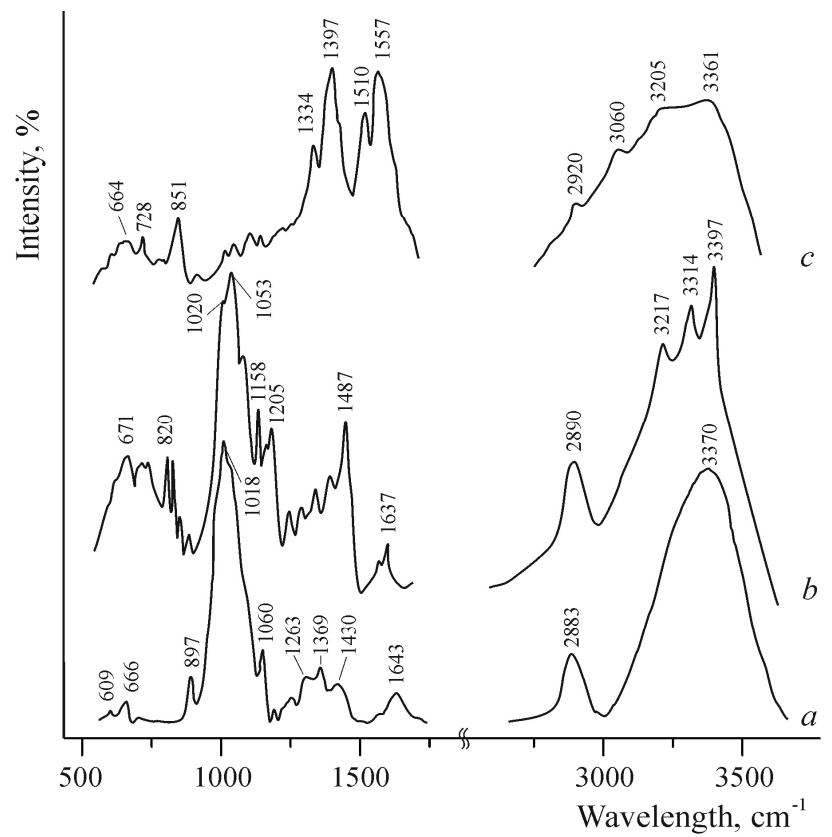

Figure 6: FTIR spectra for the PH hydrogel (a), Cell/1,10-phencyanine Zn(II) obtained after immobilization of the complex into the PH hydrogel (b), and the complex 1,10-phencyanine $\mathrm{Zn}$ (II) (c) 
The PH composite hydrogel had a wellordered structure. The PF composite hydrogel had a partially ordered structure and the crystallinity was higher. Also, the crystal sizes for this hydrogel did not differ significantly. Thus, the crystal size in the direction 1-10 was slightly higher and the one in the direction 110 was slightly lower.

Table 3

Peak wavenumbers in the FTIR spectra of the pristine and composite hydrogels ${ }^{*}$

\begin{tabular}{|c|c|c|}
\hline \multicolumn{2}{|c|}{$\begin{array}{l}\text { Peak wavenumber in the spectra } \\
\text { of the hydrogels, } \mathrm{cm}^{-1}\end{array}$} & \multirow[t]{2}{*}{ Bonds } \\
\hline Pristine & Composite & \\
\hline absent & 664 & $\mathrm{Zn}-\mathrm{N}$ groups stretching (compl) \\
\hline absent & 728 & Out-of-plane deformation of $\mathrm{H}$-atoms (compl) \\
\hline absent & 851 & $\mathrm{C}-\mathrm{C}$ and $\mathrm{C}-\mathrm{N}$ deformation (compl) \\
\hline 897 & disappear & $\mathrm{C}-\mathrm{O}-\mathrm{C}, \mathrm{C}-\mathrm{C}-\mathrm{O}$ and $\mathrm{C}-\mathrm{C}-\mathrm{H}$ deformation and stretching (cell) \\
\hline 1018 & 1020 & $\mathrm{C}-\mathrm{O}$ stretching (cell) \\
\hline 1115 & & $\mathrm{C}-\mathrm{C}, \mathrm{C}-\mathrm{OH}, \mathrm{C}-\mathrm{H}$ ring assymetric and side groups vibrations (cell) \\
\hline 1060 & 1053 & \\
\hline 1160 & 1158 & $\mathrm{C}-\mathrm{O}-\mathrm{C}$ asymmetric stretching (cell) \\
\hline absent & 1205 & (?) $\mathrm{C}-\mathrm{O}-\mathrm{C}$ symmetric stretching, $\mathrm{OH}$ plane deformation (compl) \\
\hline 1263 & 1250 & Glucose ring stretching, $\mathrm{C}-\mathrm{H}$ bending (cell) \\
\hline 1369 & 1340 & $\begin{array}{l}\text { In-plane } \mathrm{C}-\mathrm{H} \text { bending (cell) } \\
\mathrm{CAr}-\mathrm{N}, \mathrm{C}-\mathrm{C} \text { and } \mathrm{C}-\mathrm{H}(\mathrm{compl})\end{array}$ \\
\hline 1430 & 1410 & $\begin{array}{l}\mathrm{H}-\mathrm{C}-\mathrm{H} \text { symmetric and } \mathrm{O}-\mathrm{C}-\mathrm{H} \text { in-plane bending (cell) } \\
\mathrm{CAr}-\mathrm{N}, \mathrm{C}-\mathrm{C} \text { and } \mathrm{C}-\mathrm{H}(\mathrm{compl})\end{array}$ \\
\hline absent & 1487 & $\mathrm{C}=\mathrm{C}$ aromatic symmetrical stretching $(\mathrm{compl})$ \\
\hline absent & 1610 & $\begin{array}{l}\text { In-plane stretching of the conjugated } \mathrm{C}=\mathrm{C} \text { of the aromatic rings }\left(\mathrm{C}_{\mathrm{Ar}}-\right. \\
\left.\mathrm{C}_{\mathrm{Ar}}\right)(\text { compl); } \mathrm{C}=\mathrm{C} \text { and } \mathrm{C}=\mathrm{N} \text { stretching of the aromatic ring }(\mathrm{compl})\end{array}$ \\
\hline 1643 & 1637 & $\mathrm{OH}$ bending of absorbed water (cell) unspecified \\
\hline 2883 & 2890 & $\mathrm{C}-\mathrm{H}$ symmetric stretching (cell) \\
\hline overlapped & 3217 & $\mathrm{~N}^{+}-\mathrm{H}$ deformation (compl) \\
\hline overlapped & 3314 & $\mathrm{C}-\mathrm{H}$ stretching in aromatic rings (compl) \\
\hline $3370(\max )$ & overlapped & $\mathrm{O}-\mathrm{H}$ stretching (cell) \\
\hline overlapped & 3397 & $\mathrm{C}-\mathrm{C}$ in aromatic rings (compl) \\
\hline
\end{tabular}

* The bands were assigned to the corresponding bonds, according to literature ${ }^{41-51}$

Designations in brackets within the table: (cell) stands for cellulose, (compl) - complex, (?) - "unspecified

Functional and chemical composition of the samples according to the FTIR study

Figure 6 shows the FTIR spectra for (a) the PH hydrogel, (b) the PH composite hydrogel and (c) 1,10-phencyanine Zn(II) complex.

The spectrum for the hydrogel (Fig. 6, a) contained the characteristic absorption bands of

In the first spectral region, there are absorption bands at $897 \mathrm{~cm}^{-1}$ (Group $\mathrm{C}_{1}$ ), the dominant broad band with the maximum at $1018 \mathrm{~cm}^{-1}$ (stretching $\mathrm{C}-\mathrm{O}$ ) with a shoulder at $1115 \mathrm{~cm}^{-1}$ (ring asymmetric stretching), $1160 \mathrm{~cm}^{-1} \quad(\mathrm{C}-\mathrm{O}-\mathrm{C}$ asymmetric stretching), $1263 \mathrm{~cm}^{-1} \quad(\mathrm{C}-\mathrm{H}$ bending), $1369 \mathrm{~cm}^{-1}$ (C-H bending), $1430 \mathrm{~cm}^{-1}$ ( $\mathrm{H}-\mathrm{C}-\mathrm{H}$ symmetric bending) and $1643 \mathrm{~cm}^{-1}$ (-OH of water absorbed from cellulose). In the region of $2500-3700 \mathrm{~cm}^{-1}$, there are bands at $2883 \mathrm{~cm}^{-1}$ (C$\mathrm{H}$ symmetric stretching) and the broadest band appeared with the maximum at $3370 \mathrm{~cm}^{-1}$. This one is related to the valence vibration of cellulose polymorph II in spectral ranges 600$2000 \mathrm{~cm}^{-1}$ and $2500-3700 \mathrm{~cm}^{-1}$. FTIR studies of different samples of cellulose II, including those regenerated from solutions, were studied and described. The bands were assigned according to previous literature ${ }^{41-46}$ and they were shown in parentheses below and summarized in Table 3 . hydrogen-bonded $\mathrm{OH}$ groups and is undoubtedly the superposition of some overlapped bands. In the spectrum of cellulose (the structural modification II) in the hydrogel the maximum appeared at $3370 \mathrm{~cm}^{-1}$. According to previous references, ${ }^{42,43,46}$ the absorption in this region is related to the existence of the $\mathrm{OH}$ groups included in the inter- or intra-molecular hydrogen bonds. However, due to high overlapping, the bands could not be reliably identified.

The spectrum of 1,10-phencyanine $\mathrm{Zn}$ (II) complex (Fig. 6, c) contained the absorption bands at $664,726,861,1106,1334,1397,1510$ 
and $1557 \mathrm{~cm}^{-1}$ in the range $600-2000 \mathrm{~cm}^{-1}$. The most characteristic bands of the complex are located between 700 and $1250 \mathrm{~cm}^{-1}$, and between 1300 and $1650 \mathrm{~cm}^{-1}$. In a detailed study by Schilt et al., ${ }^{47}$ the spectra of the 1-10-phen complexes contained ions of the various metals investigated and strong bands were observed in three frequency regions, namely, between $700-900 \mathrm{~cm}^{-}$ ${ }^{1}$, between 1125 and $1250 \mathrm{~cm}^{-1}$ and between 1400 $1600 \mathrm{~cm}^{-1}$. In the region between $700-900 \mathrm{~cm}^{-1}$, two strong bands appeared at approximately 725 $\mathrm{cm}^{-1}$ and $850 \mathrm{~cm}^{-1}$. The first one was assigned to the out-of-plane motions of the hydrogen atoms on the heterocyclic rings and the $850 \mathrm{~cm}^{-1}$ band was related to the hydrogen atoms on the centre ring. ${ }^{47}$ Compared to the spectra of the 1-10-phen complexes in the references ${ }^{47,48}$, similar weak bands at $664 \mathrm{~cm}^{-1}, 728 \mathrm{~cm}^{-1}$ and $851 \mathrm{~cm}^{-1}$ (slightly shifted upwards) in the region between $600-900$ $\mathrm{cm}^{-1}$ (Fig. 6, c) exist in the spectrum of the 1,10phencyanine $\mathrm{Zn}$ (II) complex. The bands at 728 $\mathrm{cm}^{-1}$ and $851 \mathrm{~cm}^{-1}$ were attributed to the out-ofplane deformation motions of proton atoms and the vibrations of $\mathrm{C}-\mathrm{C}$ and $\mathrm{C}-\mathrm{N}$ groups, respectively, as well as the proton atoms of two heterocyclic rings and central rings $\left(\mathrm{C}_{\mathrm{Ar}}-\mathrm{H}\right)$. In an earlier study, ${ }^{49}$ it was shown that all the complexes of 1,10-phen showed bands in this region due to $-\mathrm{C}-\mathrm{H}$ ring and $-\mathrm{C}=\mathrm{N}$ stretching vibrations. The same assignment can be made to the weak band at $1106 \mathrm{~cm}^{-1}$. It is also possible that the weak but quite broad absorption band at 664 $\mathrm{cm}^{-1}$ be related to the stretching vibrations of $\mathrm{Zn}-$ $\mathrm{N}$ groups shifted to higher frequencies, compared to the results obtained for the substituted 1,10phenanthrolines and reported in earlier studies. ${ }^{49}$ ${ }^{51}$ In the range from $1300 \mathrm{~cm}^{-1}$ to $1650 \mathrm{~cm}^{-1}$, where characteristic ring frequencies of heterocyclic compounds (mono-, poly- or heterocyclic) occur, ${ }^{50}$ two triplets are featured. One triplet contained intensive bands with maxima at 1334, 1397 and $1410 \mathrm{~cm}^{-1}$ (a shoulder of the band at $1397 \mathrm{~cm}^{-1}$ ) attributed to the vibrations of the bonds $\mathrm{C}_{\mathrm{Ar}}-\mathrm{N}, \mathrm{C}-\mathrm{C}$ and $\mathrm{C}-\mathrm{H}$, similar to 1,10-phenanthroline. The band at 1430 $\mathrm{cm}^{-1}$ in the spectrum of 1,10-phenanthroline seemed to be sensitive to the coordination with the metals, therefore, it shifted to lower frequencies in the spectrum of 1,10-phencyanine $\mathrm{Zn}$ (II). The second triplet consisted of the intensive bands with the maxima at 1510 and $1557 \mathrm{~cm}^{-1}$, related to the in-plane stretching vibrations of the conjugated $\mathrm{C}=\mathrm{C}$ of the aromatic rings $\left(\mathrm{C}_{\mathrm{Ar}}-\mathrm{C}_{\mathrm{Ar}}\right)$ and at $1620 \mathrm{~cm}^{-1}$ (a shoulder of the band at $1557 \mathrm{~cm}^{-1}$ ) also assigned to the stretching vibrations $\mathrm{C}=\mathrm{C}$ and $\mathrm{C}=\mathrm{N}$ aromatic ring bonds. These bands also shifted, compared to the spectrum of 1,10-phenanthroline, where they appeared at 1505,1590 and $1600 \mathrm{~cm}^{-1}$. The deformation vibrations of $\mathrm{N}^{+}-\mathrm{H}$ bonds could be also found in the same region. ${ }^{50,51}$

There is a complex band with maxima at 2920 , 3060,3205 and $3361 \mathrm{~cm}^{-1}$ in the range of 2800$3600 \mathrm{~cm}^{-1}$. The first two maxima are assigned to the stretching vibrations of $\mathrm{C}-\mathrm{H}$ groups in the aromatic rings of 1,10-phenanthroline and the vibrations of $\mathrm{O}-\mathrm{H}$ bonds in monohydrate of 1,10 phenanthroline (the presence of this compound is also possible). At the same time, the bands at 3060 and $3205 \mathrm{~cm}^{-1}$ may be assigned to the deformation vibrations of $\mathrm{N}^{+}-\mathrm{H}$ as well, while the band at $3361 \mathrm{~cm}^{-1}$ reflects the vibrations of $\mathrm{C}-\mathrm{C}$ bonds in the aromatic rings. ${ }^{49-51}$ Thus, the IR spectrum of 1,10-phencyanine Zn(II) (Fig. 6, c) was a superposition of both 1,10-phenanthroline and precursor of the complex depicted in Figure 2 , b.

The functional content of the composite hydrogel obtained after immobilization of the 1,10-phencyanine Zn(II) complex (Fig. 6, b) significantly differed from the functional composition of the pristine hydrogel (Fig. 6, a). There are essential changes in the spectral range of $600-2000 \mathrm{~cm}^{-1}$. The band at $897 \mathrm{~cm}^{-1}$ assigned to the conformational vibrations of $\mathrm{C}_{1}-\mathrm{C}_{4}$ bonds (C-O-C valence vibrations) of the anhydroglucose units in the cellulose chains and to the appearance of their changed forms disappeared. ${ }^{41}$ Two bands with the maxima at $1053 \mathrm{~cm}^{-1}$ and at $1158 \mathrm{~cm}^{-1}$ were assigned to asymmetric stretching vibrations of the cellulose ring $\mathrm{C}-\mathrm{O}-\mathrm{C}{ }^{41,42}$ The new band consisted of at least five bands with a dominant band with the maximum at $1487 \mathrm{~cm}^{-1}$ appearing in the range of 1200-1500 $\mathrm{cm}^{-1}$. The bands with smaller intensities between 1250 and $1430 \mathrm{~cm}^{-1}$ can be assigned to $\mathrm{OH}$ in-plane bending, $\mathrm{CH}$ bending, $\mathrm{CH}_{2}$ wadding and $\mathrm{CH}_{2}$ symmetric bending vibrations. The band with the maximum at 1487 $\mathrm{cm}^{-1}$ is related to the changes in the deformation vibrations of the $\mathrm{CH}-$ and $\mathrm{CH}_{2}-$ groups and inplane bending vibrations of $\mathrm{OH}$ groups. However, this band shifted to higher frequences, compared to those for natural fibers studied elsewhere. ${ }^{41,42}$ The band at $1637 \mathrm{~cm}^{-1}$ assigned to the $\mathrm{OH}$ bending of absorbed water from cellulose and the band at $2890 \mathrm{~cm}^{-1}$ related to $\mathrm{C}-\mathrm{H}$ stretching vibrations in the region $2800-3000 \mathrm{~cm}^{-1}$ were 
slightly shifted, compared to the spectrum of the untreated hydrogel. More significant changes occurred in the range of the complex absorption band around $3000-3600 \mathrm{~cm}^{-1}$. The form of this band totally changed after immobilization of 1,10phencyanine $\mathrm{Zn}$ (II) into the hydrogel. The band became asymmetric and contained three intensive bands with the peak positions at 3217,3314 and $3397 \mathrm{~cm}^{-1}$ (Fig. 6, b). According to previous studies, ${ }^{42,43,46}$ the first one is related to the intermolecular hydrogen bonds of $\mathrm{O}(6) \mathrm{H} \cdots \mathrm{O}$ and/or to the $\mathrm{O} \cdots \mathrm{H}$ stretching vibrations, the second one is related to the intermolecular hydrogen bonds of $\mathrm{O}(6) \mathrm{H} \cdots \mathrm{O}$ and the third one is assigned to the intra-molecular hydrogen bond of $\mathrm{O}(2) \mathrm{H} \cdots \mathrm{O}$. It is worth noting that the intensity of the absorbance at the wavelength higher than $3400 \mathrm{~cm}^{-1}$ sharply decreased, compared to the spectrum of the hydrogel. These results showed significantly decreasing amounts of $\mathrm{OH}$ groups included in the intra-molecular hydrogen bond of $\mathrm{O}(2) \mathrm{H} \cdots \mathrm{O}^{42,43}$

The FTIR results showed that, after immobilization of the 1,10-phencyanine $\mathrm{Zn}$ (II) complex in the hydrogel, essential changes in the chemical structure of the initial complex and in the system of hydrogen bonds of cellulose in the hydrogel occurred. Apparently, some $\mathrm{OH}$ groups

Table 4

Assignment of peaks in high-resolution solid-state ${ }^{13} \mathrm{C}$ CP/MAS NMR

\section{of the hydrogels and 1,10-phencyanine $\mathrm{Zn}$ (II)}

included into intra-molecular hydrogen bonds interacted with the immobilized complex. In general, this leads to changes in the chemical composition of the hydrogel after immobilization. The interaction with the immobilized complex initiated conformational changes of the anhydroglucose units and deformation vibrations of the groups $-\mathrm{CH}$ and $-\mathrm{CH}_{2}$ in these units. All this promotes changes of the hydrogen bond system in the cellulose chains.

In general, the obtained sample Cell/1,10phencyanine $\mathrm{Zn}(\mathrm{II})$ is the result of the diffusion immobilization of the 1,10-phencyanine $\mathrm{Zn}$ (II) complex into the bulk matrix of the cellulose hydrogel, followed by the chemical interaction of the immobilized complex and cellulose inside the hydrogel. Taking into account these considerations, the obtained samples might be qualified as hybrid organic-inorganic composites.

\section{High-resolution solid-state ${ }^{13} \mathrm{C}$ CP/MAS NMR of the pristine and composite hydrogels \\ ${ }^{13} \mathrm{C} \mathrm{CP} / \mathrm{MAS}$ NMR spectra of the pristine and composite hydrogels, as well as that of the 1,10- phencyanine $\mathrm{Zn}$ (II) complex, are displayed in Figure 7 (a, b and c, respectively). The chemical shifts in the spectra are shown in Table 4.}

\begin{tabular}{|c|c|c|c|c|c|c|c|c|c|}
\hline \multirow{3}{*}{ Sample } & \multicolumn{9}{|c|}{ Chemical shift, ppm } \\
\hline & \multicolumn{6}{|c|}{ Peaks of the carbon backbone of cellulose } & \multicolumn{3}{|c|}{ Additional peaks } \\
\hline & $\mathrm{C} 1^{*}$ & $\mathrm{C} 2^{*}$ & $\mathrm{C} 3^{*}$ & $\mathrm{C} 4^{*}$ & $\begin{array}{c}\mathrm{C}^{*} \\
\text { (really } \mathrm{C} 2,3,5 \text { ) }\end{array}$ & C6 ${ }^{*}$ & 1 & 2 & 3 \\
\hline Hydrogel & 105.4 & & & $\begin{array}{l}84.2 \\
89.1\end{array}$ & 75.2 & 63.2 & - & - & - \\
\hline $\begin{array}{l}\text { Cellulose } \\
\text { regenerated from } \\
{[\text { Emim }][\mathrm{Cl}]^{52,53^{* * *}}}\end{array}$ & 104.8 & 72.6 & 75.4 & $\begin{array}{l}84.5 \\
83.1 \\
82.8 \\
\end{array}$ & 74.8 & 62.7 & - & - & - \\
\hline $\begin{array}{l}\text { Composite } \\
\text { hydrogel }\end{array}$ & $\begin{array}{l}104.5 \\
105.4\end{array}$ & & & $\begin{array}{l}82.4 \\
84.6 \\
88.5 \\
89.3\end{array}$ & $\begin{array}{c}71.8 \\
73.0 \\
74.70 \\
75.3\end{array}$ & $\begin{array}{l}62.6 \\
65.3\end{array}$ & - & $\begin{array}{l}140.5 \\
127.8\end{array}$ & 23.8 \\
\hline $\begin{array}{l}1,10- \\
\text { phenanthroline } \\
(\mathrm{Zn}) \mathrm{II}\end{array}$ & - & - & - & - & - & - & 150.9 & $\begin{array}{l}139.7 \\
127.4\end{array}$ & 23.1 \\
\hline $\begin{array}{l}\text { 1,10-pnencyanine } \\
(\mathrm{Zn}) \mathrm{II}{ }^{58^{* *}}\end{array}$ & - & - & - & - & - & - & $\begin{array}{l}150.7 \\
145.0\end{array}$ & $\begin{array}{l}139.5 \\
138.5 \\
136.5\end{array}$ & - \\
\hline
\end{tabular}

* C1-C6 represent the carbon backbone of cellulose;

${ }^{* * *}$ The chemical shifts in the ${ }^{13} \mathrm{C}$ CP/MAS NMR spectra of the reference samples, according to refs. ${ }^{52,53,58}$

In the spectrum of 1,10-phencyanine, 1 - carbons covalently bonded to nitrogen; 2 - aromatic carbons; 3 - carbons in $-\mathrm{CH}_{2}-\mathrm{l}-\mathrm{CH}_{3}$ groups 

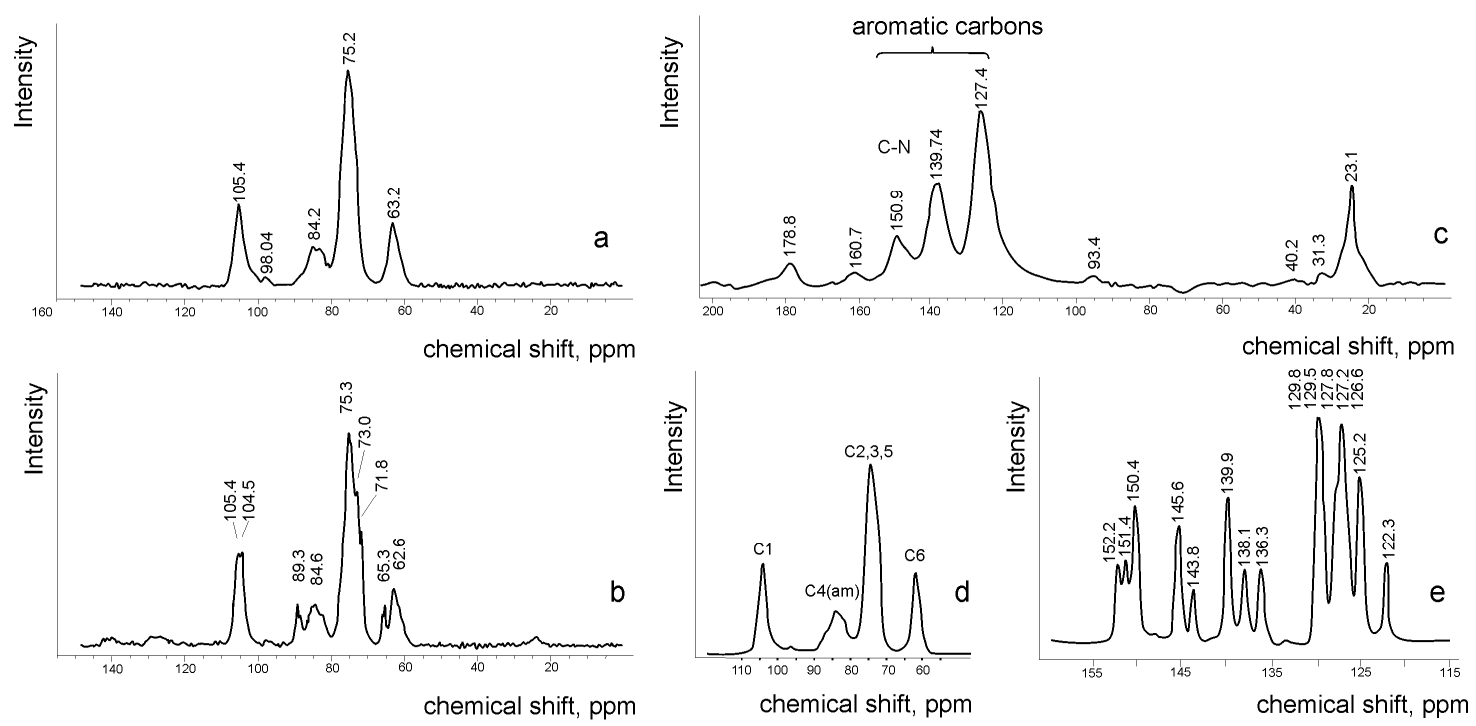

Figure 7: High-resolution ${ }^{13} \mathrm{C} \mathrm{CP} / \mathrm{MAS}$ NMR spectra of $\mathrm{PH}$ pristine hydrogel (a), PH composite hydrogel with immobilized 1,10-phencyanine $\mathrm{Zn}$ (II) (b), complex 1,10-phencyanine $\mathrm{Zn}$ (II) (c), cellulose regenerated from solution of $[$ Emim $][\mathrm{Cl}](\mathrm{d}),{ }^{52}$ a part of a solid-state ${ }^{13} \mathrm{C} \mathrm{CP} / \mathrm{MAS}$ NMR spectrum of pure 1,10 -phenanthroline (e); ${ }^{58}$ (I) Intensity and $(\delta)$ chemical shift, ppm

The chemical shifts in the spectra of the $\mathrm{PH}$ pristine hydrogel (Fig. 7, a) ranged between 105.4 ppm for $\mathrm{C} 1,84.2-89.1$ for $\mathrm{C} 4,75.2$ for $\mathrm{C} 2,3,5$, and 63.2 for C6 (Table 4). The shape of the spectrum is very similar to that of cellulose regenerated from solutions or amorphous cellulose. This is illustrated with the solid-state ${ }^{13} \mathrm{C}$ CP/MAS NMR spectra of cellulose regenerated from the solution in $[\mathrm{Emim}][\mathrm{Cl}]$ (Fig. 7, d), according to Mori et al. ${ }^{52}$

In our previous paper, ${ }^{41}$ we showed the chemical shifts of the $\mathrm{C} 4$ and $\mathrm{C} 6$ atoms in the high-resolution solid-state ${ }^{13} \mathrm{C}$ CP/MAS NMR spectra of cellulose to be the most sensitive to structural changes. The $\mathrm{C} 4$ shifts at $88-89 \mathrm{ppm}$ (strong and symmetric) were assigned to the ordered domains of the cellulose structure polymorph I, and the shifts at 83-84 ppm were assigned to the disordered domains. ${ }^{54}$ In the spectrum of the pristine hydrogel, the shift corresponding to the crystalline region could only be defined as an implicit shoulder (89.1 ppm) of the shift at 83-84 ppm due to overlapping of these two shifts. The position of the shift at 83-84 ppm in the spectra and the fuzzy shape were characteristic of the spectra of cellulose II and/or of amorphous cellulose. The amorphization of the cellulose is the most evident scenario in the formation of the hydrogel as a result of cellulose dissolution and subsequent regeneration from the solution. The position of the C6 shift at 60-66 $\mathrm{ppm}$, which was assigned to the changes in the rotational isomeric composition of the hydroxymethyl groups in the cellulose units, ${ }^{54}$ usually interpreted also on the basis of cellulose polymorphism and amorphization. ${ }^{55}$ In an earlier work, ${ }^{56}$ it was shown that there was a doublet at 62.9 and $61.4 \mathrm{ppm}$ or a broad shift at $60-62 \mathrm{ppm}$ in the spectra of cellulose II and of amorphous cellulose, respectively. In our study, C6 atoms gave a rather symmetric shift at $63.2 \mathrm{ppm}$ in the spectrum of the hydrogel. The most intense shift at $75.2 \mathrm{ppm}$ in the spectrum attributed to C2, C3, C5 carbon atoms was single and symmetric. This indicated that the chain conformation and molecular surrounding of $\mathrm{C} 2, \mathrm{C} 3$ and $\mathrm{C} 5$ carbon atoms in the hydrogel were also in agreement with the results obtained for amorphous cellulose. ${ }^{52}$

The spectrum of the composite hydrogel (Fig. 7, b) essentially differed from the spectrum of the pristine hydrogel. Some of the resonance signals became more distinct and some overlapped peaks became distinguishable. The chemical shifts in the spectrum of the composite hydrogel ranged between 104.54-105.42 ppm (doublet or triplet) for C1, 82.36-84.60-89.32 ppm for C4 (multiplet), 71.80-72.99-74.70-75.28 for C2,3,5 (quadruplet), and 62.64-65.32 for C6 (multiplet) (Table 4).

Compared to the pristine hydrogel, the spectrum of the composite hydrogel displayed novel weak shifts at $140.5,127.8$, and $23.8 \mathrm{ppm}$. In the spectrum of pure 1,10-phencyanine $\mathrm{Zn}$ (II) (Fig. 7, c), three shifts at 150.9, 139.7 and 127.4 ppm were the most intense. In a previous paper, ${ }^{57}$ 
the authors, by evaluating the electronic and spectroscopic properties of a tris $(\mathrm{N}, \mathrm{N}-$ diethyldithiocarbamato)(1,10-phenanthroline) lanthanum(III) complex, using various physical methods including solid-state ${ }^{13} \mathrm{C}$ CP/MAS NMR spectroscopy, reported that the aromatic carbons in the spectrum of 1,10-phenanthroline and its derivatives could be characterized by the resonance lines in the spectra, covering a chemical shift range of 19.9 ppm (122.3-152.2 $\mathrm{ppm}$ ), as shown herein in Figure 7, e. The shift at $150 \mathrm{ppm}$ labeled as $\mathrm{C}-\mathrm{N}$ denotes the chemical shift of the carbons covalently bonded to nitrogen, according to published data. ${ }^{57-59}$ The positions of three shifts at 150.9, 139.7 and $127.4 \mathrm{ppm}$ in the spectrum of 1,10-phencyanine Zn(II) (Fig. 7, c) exactly matched the positions in the spectrum of the above compound. The ${ }^{13} \mathrm{C}$ resonance line corresponding to methylene and/or methyl carbons in the range of $23.1 \mathrm{ppm}$ is also displayed. The above shifts were assigned to the characteristic peaks of 1,10-phenanthroline. In the spectrum of the composite hydrogel, the shifts at $140.5,127.8$, and $23.8 \mathrm{ppm}$ also ranged in the same regions. The shift at $150 \mathrm{ppm}$ was not possible to identify reliably because of very weak intensity. The obtained data confirm the fact that the immobilization of 1,10-phencyanine $\mathrm{Zn}(\mathrm{II})$ into the chemical composition of the composite hydrogel occurred.

The immobilization of 1,10-phencyanine $\mathrm{Zn}$ (II) into the hydrogel led to essential changes of the resonance peaks of $\mathrm{C}$ atoms related to the cellulose chains in the spectrum of the composite hydrogel. The peak for the $\mathrm{Cl}$ atom in the spectrum of the pristine hydrogel split into two overlapped shifts at 104.5 and $105.4 \mathrm{ppm}$. The peak for $\mathrm{C} 4$ became multiplet and displayed at least four partly overlapped peaks at 82.4, 84.6,
88.5 and $89.3 \mathrm{ppm}$, the peak for $\mathrm{C} 2,3,5$ became quadruplet and displayed four overlapped peaks at 71.8, 73.0, 74.7 and $75.3 \mathrm{ppm}$. The chemical shifts for C6 became triplet and revealed two intense peaks at 62.6 and $65.3 \mathrm{ppm}$. Generally, the spectrum exhibited not only the occurrence of the new peaks, but also demonstrated the tendency towards more highly ordered regions of the cellulose structure. This was visible in all the regions of the spectrum, as all the resonance peaks became more distinct and sharp, but most of all, in the $\mathrm{C} 4$ and $\mathrm{C} 6$ regions. The more ordered (crystalline) structure of the composite hydrogel, compared to the pristine hydrogel, was an unpredictable phenomenon. It is well known that the chemical treatment of cellulose samples leads mostly to the distorioration of the cellulose structure. However, the results obtained with ${ }^{13} \mathrm{C}$ CP/MAS NMR confirm indirectly the findings of the WAXS study.

\section{SEM study of the composite hydrogels Morphological characterization of the hydrogels}

In this section, we intentionally used complexes of different composition and different molecular mass (MM) for treating the pristine hydrogels. The purpose of this was to explore how the composition and MM of the complexes affect the morphology of the resulting composites (Table 5). The morphological properties of the pristine and composite hydrogels were evaluated using SEM. SEM images are shown in Figure 8 (a-f). Both hydrogel sets prepared from PH (Fig. 8, a, c, e) and PF (Fig. 8, b, d, f) were considered.

The samples were freeze-dried before the study. In a number of publications, it was stated that freeze-drying is exploited to preserve the gel and hydrogel structure as much as possible, before standard (high vacuum) SEM observation. ${ }^{60}$

Table 5

Content of elements on the surface and in the cross-sections of the composite hydrogels and in the immobilized complexes*

\begin{tabular}{lcccccc}
\hline \multirow{2}{*}{$\begin{array}{l}\text { Complexes } \\
\text { or hydrogels }\end{array}$} & \multicolumn{3}{c}{ Elements, wt\% } & \multicolumn{3}{c}{$\begin{array}{c}\text { MM and concentration (c) } \\
\text { of complexes in the solutions }\end{array}$} \\
\cline { 2 - 7 } & $\mathrm{C}$ & $\mathrm{H}$ & $\mathrm{N}$ & $\mathrm{Zn}$ & $\mathrm{MM}, \mathrm{g} / \mathrm{mol}$ & $\mathrm{c} \cdot 10^{3}, \mathrm{~mol} / \mathrm{L}$ \\
\hline Immobilized complex & 65.30 & 4.28 & 11.14 & 13.00 & 1508.24 & 9.0 \\
PH surface & 62.96 & - & 7.14 & 5.74 & - & - \\
PH cross-section & 66.47 & - & 4.45 & 3.62 & - & - \\
Immobilized ${ }^{* *}$ complex & 60.69 & 4.21 & 9.76 & 11.39 & 1147.83 & 9.4 \\
PF surface & 61.78 & - & 4.41 & 4.10 & - & - \\
PF cross-section & 70.13 & - & 4.86 & 5.87 & - & - \\
\hline
\end{tabular}

*Some parameters of the synthesis are included

** The overall elemental composition in the immobilized complexes 


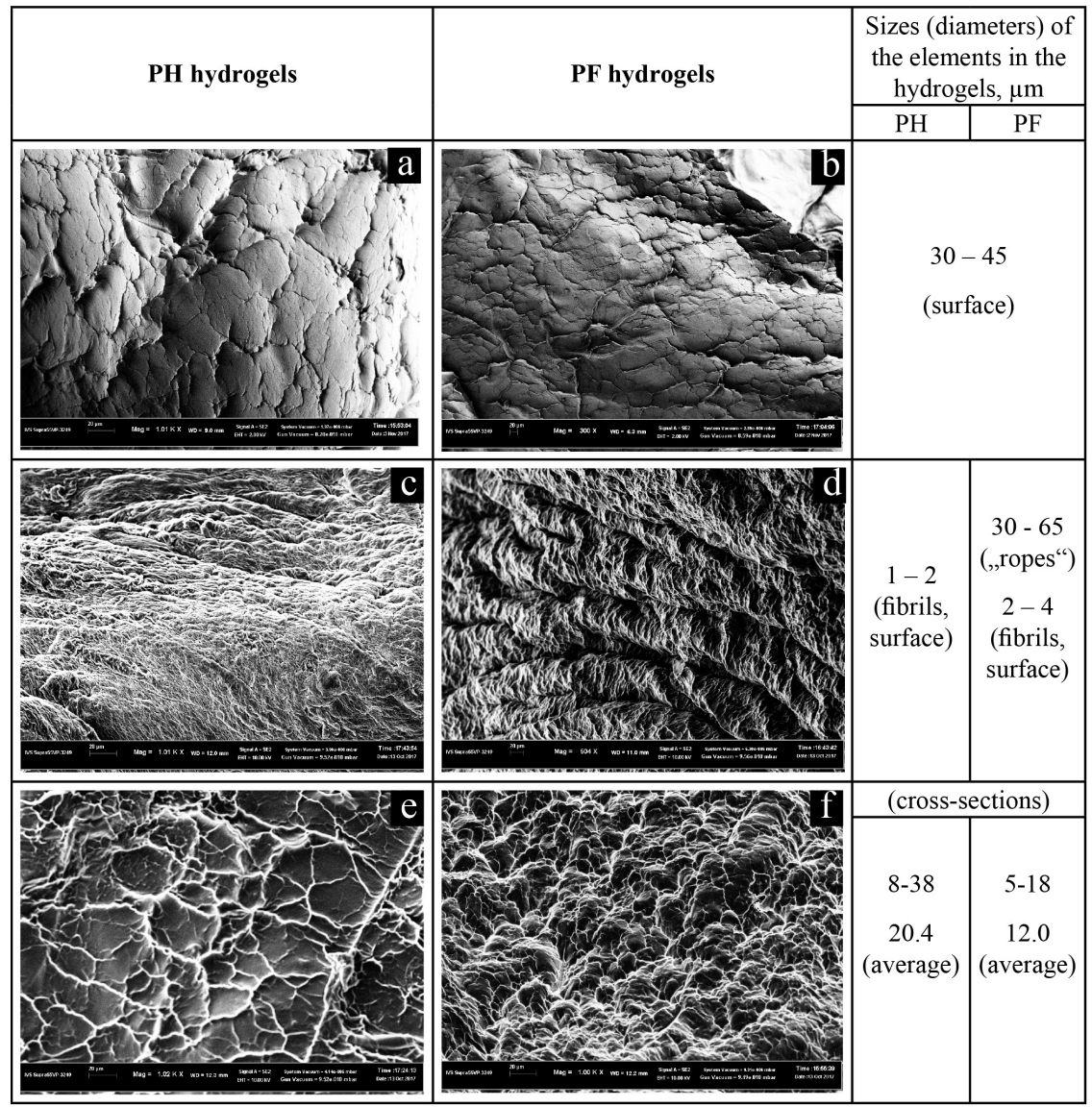

Figure 8: SEM images of the hydrogels: $\mathrm{a}, \mathrm{b}-\mathrm{PH}$ and PF pristine hydrogels, respectively, $\mathrm{c}, \mathrm{d}-\mathrm{PH}$ and PF composite hydrogels, respectively, e, f - cross-sections of PH and PF composite hydrogels, respectively

However, in some publications, there were alternative opinions that freeze-drying in water tends to disturb the original network structure as the growth of ice crystals often creates a different pore structure than that present in the hydrogel. ${ }^{61}$ Nevertheless, the freeze-drying technique is the most common when preparing samples for SEM observations because most researchers believe that there are no changes in the structure and morphology of the hydrogels.

The surfaces of the pristine hydrogels looked dense and reminiscent of hardened lava after a volcanic eruption, with cracks or ruptures and mainly fastened to each other. This morphology was observed independently of the origin of the hydrogels (Fig. 8, a and b). The elements on the surface did not have any certain shape, therefore, it was impossible to determine the sizes of the elements reliably. Nevertheless, we estimated their approximate average sizes (diameters) to be in the range between 30 and $45 \mu \mathrm{m}$.

The SEM images of the composite hydrogels revealed a completely different morphological structure from that of the pristine hydrogels. The composite hydrogels had a more or less tight surface structure, i.e. external morphology (Fig. 8, $\mathrm{c}$ and d), and anisotropic intrinsic porous morphology in the cross-sections (Fig. 8, e and f). The surface morphology of the PH composite hydrogel showed the presence of macrofibrils, which formed a heavily fibrillated surface (Fig. 8, c). The interwoven fibrils had slightly different transverse dimensions and ranged between 1 and $2 \mu \mathrm{m}$. They were arranged non-homogeneously and did not reveal any ordered structure.

The surface of the PF composite hydrogel (Fig. 8, d) seemed much denser than that of the PH composite hydrogel. Ordered fibrillar fragments shaped as twisted "ropes" could be clearly observed. The "ropes" were located regularly and their sizes in the transverse dimensions were from 35 to $65 \mu \mathrm{m}$. With higher magnification, it could be seen that the fragments were formed with fibrils swirled in spirals on the surface, which looked loose and highly porous. The thickness (diameter) of the fibrillar filaments 
that formed the "ropes" slightly differed, ranging between 2 and $4 \mu \mathrm{m}$. However, each fibril, probably, appeared to be composed of several microfibrils.

The cross-sections of the composite hydrogels allowed identifying an open-cell porous network with a three-dimensional interconnected microstructure. The interconnection between the pores could be assigned to the regular macroporous structure packed with pores throughout the hydrogel composites. Numerous studies on the morphological structure of hydrogels based on cellulose and cellulose derivatives have shown similar results. We consider here some of them. In the paper of Gan et al., ${ }^{62}$ SEM observations showed that hydrogels from regenerated cellulose and aerogels prepared from cellulose carbamate of Kenaf pulp dissolved in the urea-alkaline system and then regenerated had macroporous structure. The authors considered that the trapped water in the cellulose hydrogel turned into ice crystals during the freeze-drying process with phase separation, followed by subsequent sublimation, which caused the formation of voids in the cellulose aerogels with the pore size from 145 to $165 \mu \mathrm{m}$. In another study, ${ }^{63}$ by examining super-absorbent hydrogels prepared by graft copolymerization of chitosan and different synthetic monomers using gamma irradiation, the authors supposed that the pores were the regions of water permeation and interaction sites of external stimuli with the $\mathrm{OH}$ groups of the hydrogels. Therefore, the porous structure was the predominant reason for the high swelling ratios of the hydrogels. The same conclusion was drawn in our previous paper. ${ }^{20} \mathrm{We}$ studied the self-assembly of hydrogels spontaneously formed from cellulose solutions in $\mathrm{DMAc} / \mathrm{LiCl}$ and established that the shape and stability of the hydrogels corresponded to the strong interaction of water molecules with the $\mathrm{OH}$ groups of cellulose and to the formation of a novel network of $\mathrm{H}$-bonds between the $\mathrm{OH}$ groups and water. The water molecules bound to the $\mathrm{OH}$ groups of the cellulose were randomly arranged in the volume of the hydrogels. In another publication, ${ }^{60}$ the authors concluded that the creation of an interconnected network of micro- or macropores in the gel represents a sophisticated and accurate way to further control its bulk properties, including the swelling extent and kinetics. They also established that the porous hydrogels can retain higher amounts of water compared to non-porous ones, and concluded that this property was due to additional capillary retention. The data obtained with SEM by Lodhi et $a l^{64}$ confirmed the above results for the hydrogel extracted from the seeds of sweet basil. The authors considered that well-dispersed crosssections in the interconnected macropores structure of the hydrogel, having an average pore size of $1.92 \pm 3.83 \mu \mathrm{m}$, provided an easy passage to the solvents, which was essential for fast and high swelling of the hydrogel. In another work, ${ }^{65}$ SEM analysis of the porous architecture and properties of anisotropic nanocellulose foams prepared by ice templating of cellulose nanofibril suspensions, subjected to grinding with different specific energy input, was performed. The foams demonstrated different cross-section morphology, depending on the energy input, and the foams exhibited a well-defined porous structure with pore sizes bigger than $30 \mu \mathrm{m}$ and an open honeycomb-like structure.

A comparison of the SEM results for the hydrogels studied here and the mentioned examples shows that there are certain similarities and differences between the composite hydrogels and the samples considered above. Some common features can be identified, as follows:

- we prepared composite hydrogels with high porous morphology in bulk; the surface of the hydrogels was loose and permeable to water;

- the inner structure of the hydrogels was composed of pores that permeated the entire areas; the pores were randomly distributed and had cellular structure; due to this, the hydrogels retained great amounts of water;

- the hydrogels exhibited long-term stability in water.

Despite the common features, significant differences were also established. Commonly, cellulose-based hydrogels were prepared after dissolving cellulose samples or cellulose derivatives in solvent systems and subsequent regeneration from the solutions and/or by using the cross-linkers to interconnect the cellulose chains and to form a net structure inside the hydrogels. The main and especially important advantage of this study was the following: we used the pristine hydrogels obtained after regeneration without using any anti-coagulants and cross-linkers and without external treatments. Moreover, the composite hydrogels were synthesized via direct heterogeneous reaction between the pure cellulose hydrogel and the 1,10phencyanines $\mathrm{Zn}(\mathrm{II})$ complex. 
Pore size and arrangement in the composite hydrogels. Factors affecting the penetration of the complexes into the hydrogels

Figure 8 (e and $\mathrm{f}$ ) exhibits the loose and macroporous internal structure of the composite hydrogels that was clearly visible in the crosssections. However, the inner structure in the cross-section of PF looked denser than that of PH. The pores in the cross-section showed different shapes, but, in general, they could be described as cellular with a honeycomb-like structure for both hydrogels. The pores seemed to be separated by fibrillary fragments framing them at the junctions. In some cases, these fragments may appear to act as peculiar bridges. The pores were randomly distributed and their sizes differed for the $\mathrm{PH}$ and PF hydrogels. They were in the ranges of 8-38 $\mu \mathrm{m}$ and 5-18 $\mu \mathrm{m}$, whereas the average pore sizes were $20.4 \mu \mathrm{m}$ and $12.0 \mu \mathrm{m}$, for the $\mathrm{PH}$ and $\mathrm{PF}$ hydrogels, respectively.

The experimental parameters in the synthesis of the hydrogels strongly impacted the efficiency of the synthesis and the properties of the composite hydrogels, including the pore sizes. In order to confirm this assumption, first of all, we applied complexes with different molecular mass (MM) for treating the pristine hydrogels. The MM of the complex used for treating the PH hydrogel was $1508.24 \mathrm{~g} / \mathrm{mol}$ and the MM of the complex used for treating the PF hydrogel was lower $(1147.83 \mathrm{~g} / \mathrm{mol})$. The concentration of the complexes in the solutions was similar $\left(9.0 \cdot 10^{-3}\right.$ and $9.4 \cdot 10^{-3}$, for PH and PF hydrogels, respectively). The results of the impact of MM on the content of the main elements on the surface and in the cross-sections of the composite hydrogels were obtained with SEM-EDS and listed in Table 5.

The results showed that:

- the higher the MM of the immobilized complex, the higher the contents of $\mathrm{Zn}(5.74 \mathrm{wt} \%)$ and $\mathrm{N}(7.14 \mathrm{wt} \%)$ on the surface of the $\mathrm{PH}$ composite hydrogel, the contents of the same elements were lower in the cross-sections;

- the lower the MM of the immobilized complex, the lower the content of $\mathrm{Zn}(4.10 \mathrm{wt} \%)$ and $\mathrm{N}$ (4.41 wt\%) on the surface of the PF composite hydrogel. In this case, the content of the same elements was higher in the crosssections. Moreover, the PF composite hydrogels contained higher amounts of $\mathrm{Zn}(5.87 \mathrm{wt} \%)$ and $\mathrm{N}$ $(4.86 \mathrm{wt} \%)$ in the bulk than the amounts of $\mathrm{Zn}$
(3.62 wt\%) and $\mathrm{N}(4.45 \mathrm{wt} \%)$ in the bulk of the $\mathrm{PH}$ composite hydrogels;

- the impact of the MM of the embedded complex on the efficiency of the immobilization was detected. In other words, the higher the MM of the complex, the less is its penetration into the hydrogel bulk, and most of the complex remained on the surface.

\section{Some closing remarks}

Based on numerous published results on the modification of cellulose-based hydrogels, it could be concluded that the formation of the pores and their sizes depend mainly on both the structure of the cellulose in the hydrogels and the synthesis procedure. In our opinion, the morphology of the hydrogel surfaces should play an important role also. In our case, when the experimental conditions were the same for most trials, the structure of the cellulose and the surface morphology should be the major parameters affecting the penetration of the complexes into the hydrogels. The surface morphology of both pristine hydrogels was very similar. The morphology of the composite hydrogels after immobilization differed substantially from that of the pristine hydrogels. In the case of the $\mathrm{PH}$ hydrogel, disordered and entangled fibres formed irregularly distributed patterns, i.e. the hydrogel surface was subjected to loosening by the immobilization of the complex and further synthesis resulted in the formation of a porous structure. In the case of the PF hydrogel, the fibrillar fragments were quite ordered and continuously arranged, shaped as regular "ropes" (Fig. 8, c, d), i.e. the dense surface of the pristine hydrogel seemed to be disordered first. However, this disordered structure partially self-organized as a result of the interaction between the complex and the cellulose in the hydrogel. In the formed porous structure, the pore sizes were lower compared to those for the $\mathrm{PH}$ composite hydrogels. Thus, the immobilization of the complexes affected very similar hydrogel surfaces in different ways.

The pristine PH and PF hydrogels had similar crystallinity values, according to WAXS results presented above (Table 2). After the immobilization of the complex, the $\mathrm{PH}$ composite hydrogel had a purely ordered structure. The PF composite hydrogel had a more ordered structure and the crystallinity was slightly higher. The crystal sizes did not differ considerably either. 
Thus, the difference in the crystallinity values was not significant enough to explain the variations in the penetration of the complexes into the pristine hydrogels and the formation of the pore systems in the composite hydrogels. In spite of the similar crystallinity values, an essential difference in the overall crystalline structure of the composite hydrogels consisted in the additional formation of the crystalline phase of the cellulose I allomorph in the PF composite hydrogel. Evidently, the formation of this phase was initiated with the immobilization of the complex.

It is worth noting that the pore size in the PF hydrogel was about twice smaller (on average) than that in the $\mathrm{PH}$ hydrogel. Obviously, the complex with lower MM used for the treatment of the PF hydrogel allowed its penetration to a greater extent through the pores of smaller size into the hydrogel bulk. Thus, the experimental parameters in the synthesis of the hydrogels strongly impacted the properties of the composite hydrogels, including the pore sizes.

\section{CONCLUSION}

- Hybrid composite hydrogels were newly synthesized via heterogeneous immobilization of 1,10-phenanthrocyanine zinc(II) complexes into cellulose hydrogels initially prepared from solutions of flax fibers and hardwood pulp in $\mathrm{DMAc} / \mathrm{LiCl}$. The synthesis procedure was onepot, simple and did not require any special techniques or equipment.

- The composite hydrogels were superswollen 3D systems and retained large amounts of water. They demonstrated high porosity and longterm stability.

- FTIR revealed the chemical interaction between the immobilized complexes and cellulose inside the hydrogels resulting from the synthesis of the composite hydrogels.

- According to WAXS results, the crystallinity determined on the basis of cellulose II was slightly higher for the PF composite hydrogels than for the $\mathrm{PH}$ hydrogels. The formation of the crystalline phase of the cellulose I allomorph in the PF composite hydrogel was detected. The additional crystallization of the cellulose in the composite hydrogels resulting from the immobilization of the complexes was confirmed by ${ }^{13} \mathrm{C}$ CP/MAS NMR spectroscopy.

- According to SEM, the surface morphology of the pristine hydrogels was loosened up by the treatment with the complexes and led to their penetration into the bulk of the hydrogels, successful interaction with the cellulose and, as a result, the formation of the pore systems. The maximum contents of $\mathrm{Zn}$ and nitrogen were found in the PF composite hydrogels: $\mathrm{Zn}$ contents were $4.10 \mathrm{wt} \%$ and $5.87 \mathrm{wt} \%$ on the surface and in the bulk, respectively, and nitrogen contents were $4.41 \mathrm{wt} \%$ and $4.86 \mathrm{wt} \%$, respectively.

- The experimental parameters of the synthesis strongly impacted its efficiency and the properties of the composite hydrogels, including the pore sizes.

ACKNOWLEDGMENTS: The authors are grateful to E. N. Valsova (IMC RAS, St. Petersburg, Russia) for recording the FTIR spectra, to Karim Saurov Shahriar (University of Helsinki, Finland) for performing WAXS experiments and to Dr. V. N. Demidov (St. Petersburg, Russia) for participation in the experiments and in the discussion of the results.

\section{REFERENCES}

1 A. Freyburger, $\mathrm{PhD}$ Dissertation, Universitat Regensburg, Germany, 2018, https://epub.uniegensburg.de/37181

2 R. S. Dassanayake, S. Acharya and N. Abidi, in "Advanced Sorption Process Applications", edited by S. Edebali, IntechOpen, 2018, pp. 1-24, https://doi.org/10.5772/intechopen.80898

3 J. Liun, S. Willför and C. Xu, Bioact. Carbohyd. Dietary Fibre, 5, $31 \quad$ (2015), https://doi.org/10.1016/j.bcdf.2014.12.001

4 H. Shaghaleh, X. Xu and S. Wangab, RSC Adv., 8, 825 (2018), https://doi.org/10.1039/c7ra11157f

5 G. M. Raghavendra, K. Varaprasad and T. Jayaramudu, in "Nanotechnology Applications for Tissue Engineering”, edited by S. Thomas, Y. Grohens and N. Ninan, William Andrew Publ., 2015, pp. 21-44, https://doi.org/10.1016/b978-0-323-32889-0.00002-9

6 S. K. Ramamoorthy, M. Skrifvars and A. Persson, Polym. Rev., 55, $107 \quad$ (2015), https://doi.org/10.1080/15583724.2014.971124

7 R. P. Babu, K. O'Connor and R. Seeram, Progress Biomater., 2, 8 (2013), https://doi.org/10.1186/21940517-2-8

8 Directorate-General for Research and Innovation (European Commission), Fraunhofer ISI, University of Bologna, Task 3 of "Study on Support to R\&I Policy in the Area of Bio-based Products and Services", Publications Office of the EU, 2018, https://doi.org/10.2777/85805

9 M. Paterson and J. F. Kennedy, in "Immobilization of Enzymes and Cells", edited by Ed. G. F. Bickerstaff, Humana Press, 1997, pp. 153-165, https://doi.org/10.1385/0896033864 
10 M. D. Lilly, Methods Enzymol., 44, 46 (1976), https://doi.org/10.1016/S0076-6879(76)44006-5

11 N. Kotelnikova, S. A. Mikhailova and E. N. Vlasova, Russian J. Appl. Chem., 80, 322 (2007), https://doi.org/10.1134/s1070427207020309

12 N. E. Kotelnikova, G. Wegener, T. Paakkari, R. Serimaa, V. N. Demidov et al., Russian J. General Chem.,73, 418

(2003),

https://doi.org/10.1023/A:1024914104932

${ }^{13}$ K. Pirkkalainen, U. Vainio, K. Kisko, T. Elbra, T. Kohout et al., J. Appl. Crystallogr., 40, s489 (2007), https://doi.org/10.1107/s0021889806055804

14 U. Vainio, K. Pirkkalainen, K. Kisko, G. Goerigk, N. E. Kotelnikova et al., Eur. Phys. J. D, 42, 93 (2007), https://doi.org/10.1140/epjd/e2007-00015-y

15 K. Pirkkalainen, K. Leppänen, U. Vainio, M. A. Webb, T. Elbra et al., Eur. Phys. J. D, 49, 333 (2008), https://doi.org/10.1140/epjd/e2008-00180-5

16 N. E. Kotelnikova and A. M. Mikhailidi, Cellulose Chem. Technol., 45, $585 \quad$ (2011), http://www.cellulosechemtechnol.ro/pdf/CCT45,910(2011)/p.585-592.pdf

17 X. Shen, J. L. Shamshina, P. Berton, G. Gurau and R. D. Rogers, Green Chem., 18, 53 (2016), https://doi.org/10.1039/c5gc02396c

18 B. V. Mohite, S. H. Koli and S. V. Patil, in "Cellulose-Based Superabsorbent Hydrogels", edited by I. H. Mondal, Springer, Cham, 2018, pp. 1-22, https://doi.org/10.1007/978-3-319-76573-0_2-1

19 M. Pandey, M. C. I. Mohd Amin, N. Mohamad, N. Ahmad and Sh. Muda, Polym.-Plast. Technol. Engin., $\quad$ 52, $1510 \quad$ (2013), https://doi.org/10.1080/03602559.2013.820755

20 A. Mikhailidi, Sh. Karim Saurov, S. Andersson and N. Kotelnikova, TAPPI J., 17, 81 (2018), https://doi.org/10.32964/tj17.02.81

21 A. M. Ribeiro, M. Magalhães, F. Veiga and A. Figueiras, in "Cellulose-Based Superabsorbent Hydrogels", edited by I. H. Mondal, Springer, Cham, 2018, pp. 1-29, https://doi.org/10.1007/978-3-31976573-0_41-1

22 S. M. F. Kabir, P. P. Sikdar, B. Haque, M. A. R. Bhuiyan, A. Ali et al., Progress Biomater., 7, 153 (2018), https://doi.org/10.1007/s40204-018-0095-0

23 C. Katepetch, R. Rujiravanit and H. Tamura, Cellulose, $\quad 20, \quad 1275 \quad$ (2013), https://doi.org/10.1007/s10570-013-9892-8

24 N. C. S. Selvam, S. Narayanan, L. J. Kennedy and J. J. Vijaya, J. Environ. Sci., 25, 2157 (2013), https://doi.org/10.1016/s1001-0742(12)60277-0

${ }_{25}$ S. A. Ovalle-Serrano, V. S. Carrillo, C. BlancoTirado, J. P. Hinestroza and M. Y. Combariza, Cellulose, 22, $1841 \quad$ (2015), https://doi.org/10.1007/s10570-015-0620-4

26 V. N. Demidov, S. A. Simanova, A. I. Savinov and T. B. Pakhomova, Russian J. General Chem., 79, 2807 (2009), https://doi.org/10.1134/S1070363209120391
V. N. Demidov and T. B. Pakhomova, in Procs. IX International Conference on Bioantioxidants, Moscow, September 29 - October 2, 2015, p. 51

C.-M. Liu, Y.-L. Hou, J. Zhang and S. Gao, Inorg. Chem., $\quad 41, \quad 140 \quad$ (2002), https://doi.org/10.1021/ic010735k

V. N. Demidov, A. M. Mikhalidi, E. N. Vlasova and N. E. Kotelnikova, Fiber Chem., 50, 383 (2019), https://doi.org/10.1007/s10692-019-09994-3

S. Kundakçi, E. Karadağ and Ö. B. Üzüm, J. Encapsul. Ads. $\quad$ Sci., $\quad 1, \quad 7 \quad$ (2011), https://doi.org/10.4236/jeas.2011.11002

S. J. Gregg and K. S. W. Sing, in "Adsorption, Surface Area and Porosity", Academic Press, Wiley-VCH Verlag GmbH \& Co. KGaA, Weinheim, 1967, https://doi.org/10.1002/bbpc.19670710837

Sh. Karim Saurov, A. Mikhailidi, K. Svedström and N. Kotelnikova, Cellulose Chem. Technol., 53, 885 (2019),

https://doi.org/10.35812/cellulosechemtechnol.2019.53 .86

P. Scherrer, in "Nachrichten von der Gesellschaft der Wissenschaften zu Göttingen”, MathematischPhysikalische Klasse, Weidmannsche Buchhandlung, Berlin, 1918, pp. 98-100, http://eudml.org/doc/59018

J. Obradovic, H. Wondraczek, P. Fardim, L. Lassila and P. Navard, Cellulose, 21, 4029 (2014), https://doi.org/10.1007/s10570-014-0403-3

J. Rebiere, M. Heuls, P. Castignolles, M. Gaborieau, A. Rouilly et al., Anal. Bioanal. Chem., 408, 8403 (2016), https://doi.org/10.1007/s00216-016-9958-1ff. ffhal-01601638f

D. Ciolacu, F. Ciolacu and V. I. Popa, Cellulose Chem Technol., 45, 13 (2011), http://cellulosechemtechnol.ro/pdf/CCT12(2011)/p.13-21.pdf

A. D. French, Cellulose, 21, 885 (2014), https://doi.org/10.1007/s10570-013-0030-4

K. Karimi and M. J. Taherzadeh, Bioresour. Technol., 200, $1008 \quad$ (2016), https://doi.org/10.1016/j.biortech.2015.11.022

Zh. Ling, Sh. Chen, X. Zhang, K. Takabe and F. Xu, Sci. Rep., 7, 10230 (2017), https://doi.org/10.1038/s41598-017-09885-9

T. G. Fawcett, C. E. Crowder, S. N. Kabekkodu, F. Needham, J. A. Kaduk et al., Powder Diffr., 28, 18 (2013), https://doi.org/10.1017/s0885715612000930

N. E. Kotelnikova, Yu. V. Bikhovtsova, A. M. Mikhailidi, M. V. Mokeev, N. N. Saprikina et al., Cellulose Chem Technol., 48, 643 (2014), http://cellulosechemtechnol.ro/pdf/CCT7-

8(2014)/p.643-651.pdf

M. Fan, D. Dai and B. Huang, in "Fourier Transform", edited by S. Salih, IntechOpen, 2012, pp. 45-68, https://doi.org/10.5772/35482

27 F. Carrillo, X. Colom, J. J. Sunol and J. Saurina, Eur. Polym. J., 40, $2229 \quad$ (2004), https://doi.org/10.1016/j.eurpolymj.2004.05.003 
28 L. V. Haule, C. M. Carr and M. L. A. Rigout, Carbohyd. Polym., 144, 131 (2016), https://doi.org/10.1016/j.carbpol.2016.02.054

29 T. Baldinger, J. Moosbauer and H. Sixta, Lenzing Berichte, 79, 15 (2000), https://www.researchgate.net/publication/284686755

30 D. Fengel, Holzforschung, 46, 283 (1992), https://doi.org/10.1515/hfsg.1992.46.4.283

31 A. A. Schilt and R. C. Taylor, J. Inorg. Nucl. Chem., 9, 211 (1959), https://doi.org/10.1016/00221902(59)80224-4

32 L. Zeng, Master's Theses, Eastern Illinois University, USA, 1995, 67 p., https://thekeep.eiu.edu/theses/1854

33 S. Khaled, S. K. Ahmed and M. Z. Ahmed, Chem. Sci. $\quad$ Trans., $\quad 2, \quad 1222 \quad$ (2013), https://doi.org/10.7598/cst2013.591

34 S. P. Kumar, R. Suresh, K. Giribabu, R. Manigandan, S. Munusamy et al., Int. J. Chem. Tech. Res., $\quad 6, \quad 3280 \quad$ (2014), http://sphinxsai.com/2014/vol6_6_ICMCT/2/(32803283)ICMCT14.pdf

35 R. C. Smith, PhD Dissertation, Iowa State University, USA, 1961, 278 p, https://doi.org/10.31274/rtd-180813-4754

36 T. Mori, E. Chikayama, Y. Tsuboi, N. Ishida, N. Shisa et al., Carbohyd. Polym., 90, 1197 (2012), https://doi.org/10.1016/j.carbpol.2012.06.027

37 T. Liitiä, PhD Dissertation, Helsinki University, Finland, 2002, $46 \quad$ p., https://www.researchgate.net/publication/47932636

38 N. E. Kotelnikova, A. Yu. Elkin, A. I. Kol'tsov, G. A. Petropavlovskii and Yu. N. Sazanov, in "Metody issledovaniya tsellyulozy" (Methods for Studying Cellulose), Zinatne, 1988, pp. 61-65

39 S. Maunu, T. Liitiä, S. Kauliomäki, B. Hortling and J. Sundquist, Cellulose, 7, 147 (2000), https://doi.org/10.1023/A:1009200609482
40 M. Wada, L. Heux and J. Sugiyama, Biomacromolecules, $\quad 5, \quad 1385 \quad$ (2004), https://doi.org/10.1021/bm0345357

${ }^{41}$ V. Gowda, R. S. Laitinen, V. V. Telkki, A. C. Larsson, O. N. Antzutkin et al., Dalton Trans., 45, 19473 (2016), https://doi.org/10.1039/C6DT03705D

42 P. M. Szell, S. A. Gabriel, R. D. Gill, S. Y. Wan, B. Gabidullin et al., Acta Crystallogr., C, Struct. Chem., 73, 157

(2017), https://doi.org/10.1107/S2053229616015023

43 Spectral Database for Organic Compounds (SDBS), https://sdbs.db.aist.go.jp

${ }^{44}$ Ch. Demitri, M. Madaghiele, M. G. Raucci, A. Sannino and L. Ambrosio, in "Hydrogels: Smart Materials for Biomedical Applications", edited by L. Popa, IntechOpen, 2019, pp. 2-28, http://dx.doi.org/10.5772/intechopen.80986

45 H. Sehaqui, Q. Zhou, O. Ikkala and L. A. Berglund, Biomacromolecules, 12, $3638 \quad$ (2011), https://doi.org/10.1021/bm2008907

46 S. Gan, S. Zakaria, C. H. Chia, R. S. Chen, A. V. Ellis et al., PLoS ONE, 12, e0173743 (2017), https://doi.org/10.1371/journal.pone.0173743

47 N. M. A. El-S. Deghiedy, Master's Thesis, National Center for Radiation Research and Technology, Cairo, Egypt, 2010, 169 p., https://inis.iaea.org/collection/NCLCollectionStore/_P ublic/43/081/43081203.pdf

48 B. A. Lodhi, M. A. Hussain, M. Sher, M. T. Haseeb, M. U. Ashraf et al., Adv. Polym. Tech., 2019, Article ID $9583516 \quad$ (2019), https://doi.org/10.1155/2019/9583516

${ }^{49}$ K. Kriechbaum, P. Munier, V. ApostolopoulouKalkavoura and N. Lavoine, ACS Sustain. Chem. Eng., 6, 11959

(2018), 